\title{
LOS CONJUNTOS PROTOCELTIBERICOS DE LA MESETA ORIENTAL: EJEMPLOS DE LA NECRÓPOLIS DE CARRATIERMES (MONTEJO DE TIERMES, SORIA)
}

\author{
POR
}

\author{
JOSE LUIS ARGENTE OLIVER (") \\ ADELIA DIAZ DIAZ (**) \\ ALBERTO BESCOS CORRAL (**) \\ ANTONIO ALONSO LUBIAS (***)
}

\begin{abstract}
RESUMEN La excavación de la necrópolis celtibérica de Carratiermes ha proporcionado hasta el presente importante información sobre este tipo de yacimientos; los resultados confirman en parte los datos establecidos hace años, mientras que, por otro lado, ofrecen nuevas perspectivas para el conocimiento de tales estaciones. Tal vez, la aportación más interesante y novedosa sea la que se refiere al momento protoceltibérico y la diferenciación en él de dos tipos distintos de ajuares funerarios.
\end{abstract}

ABSTRACT The excavation of the Carratiermes Celtiberian cemetery has revealed important information about this kind of site; on the one hand, the results confirm the data established many years ago, while, on the other hand, it offers new perspectives for the understanding of such sites. Perhaps the most interesting new contribution is that which is referred to as the protoceltiberian period and the distinction between two different types of grave goods.

Palabras clave Necrópolis celtibérica. Protoceltibérico. Pectoral. Espiraliformes. Carratiermes. Tiermes. Soria.

Key words Celtiberian Necropolis. Protoceltiberian. Pectoral cross. Spiral shapes. Carratiermes. Tiermes. Soria.

\section{INTRODUCCION}

La investigación en el yacimiento arqueológico de Tiermes está centrada, durante las últimas campañas, en la necrópolis celtibérica de Carratiermes, que ha proporcionado hasta el presente un

(`) Director del Museo Numantino y de las Excavaciones Arqueológicas de Carratiermes. Museo Numantino.

(“) Codirectores en las Excavaciones Arqueológicas de Carratiermes.

(“*) Colaborador de las Excavaciones Arqueológicas de Carratiermes y autor de los dibujos que se presentan. 
conjunto de enterramientos importante no sólo cuantitativamente, sino también por el aporte de información sobre estructuras y formas funerias, rito, piezas que constituyen los ajuares inventariados, objetos singulares, etc..; todo ello permitirá, cuando concluyan los trabajos de campo, llevar a cabo un estudio en profundidad tanto de la propia necrópolis de Carratiermes, como del área de su entorno, en la que se incluyen los cementerios ya conocidos y registrados en la bibliografía pertinente (Aguilera y Gamboa, 1916), así como las que en la actualidad se encuentran en fase de investigación (Argente Oliver, 1988 y 1989 en prensa, y 1990 b y c), García-Soto Mateos (1981 y 1990) y Cerdeño Serrano.

Carratiermes se ubica a unos 900 metros al nordeste de la ermita románica de Nuestra Señora de Tiermes (enclavada en el solar de la antigua Termes o Tiermes). La superficie que ocupa la necrópolis se aproxima, según nuestras estimaciones, a los 35.000 metros cuadrados, y en ella existen espacios vacíos de enterramientos (Argente Oliver y Díaz Díaz, 1990; Argente Oliver, Díaz Díaz y Bescós Corral, 1990). Actualmente se ha explorado entre un 15 a $20 \%$ del total calculado para el desarrollo del cementerio (Figs. 1 y 2).

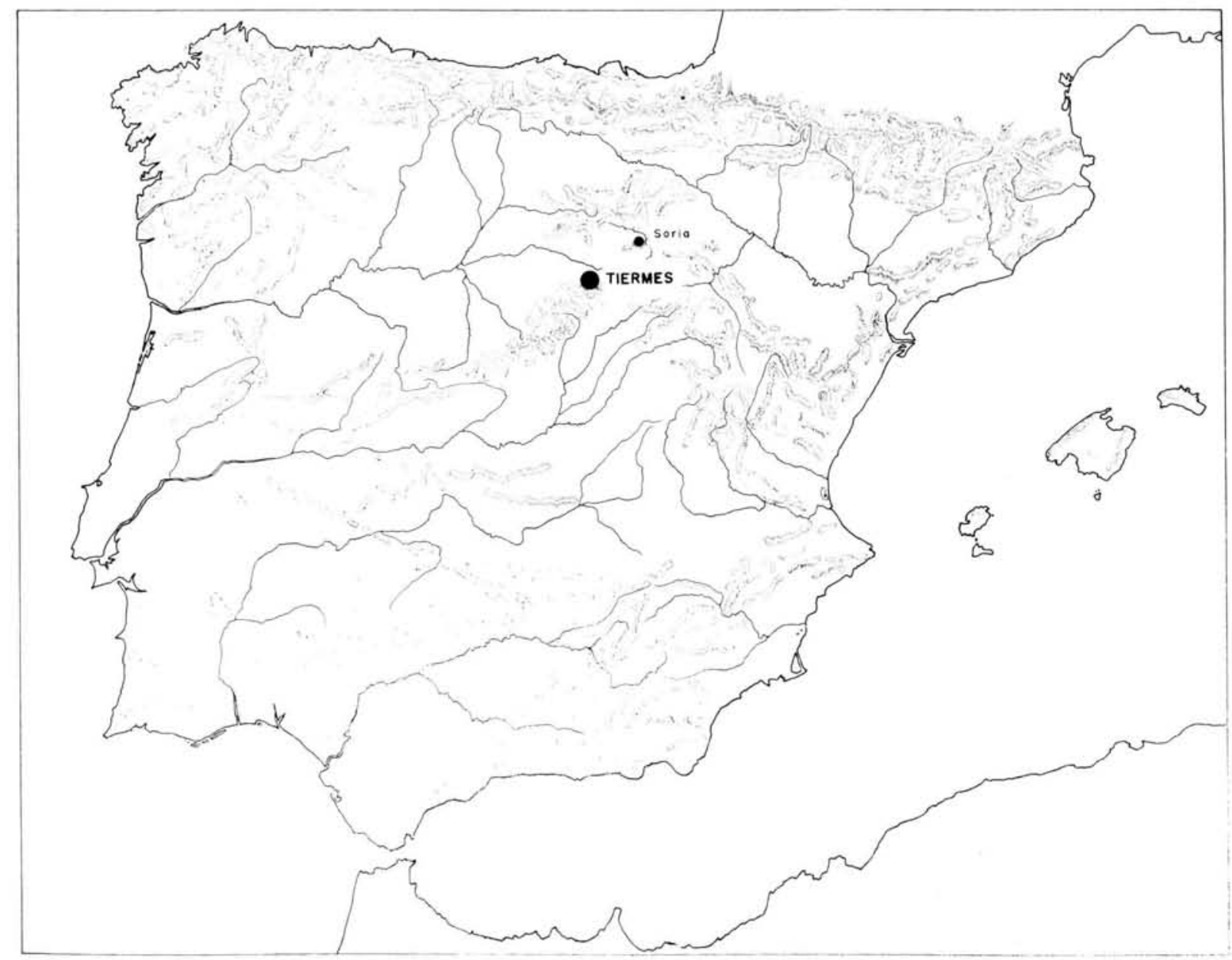

Fig. 1.-Situación de Tiermes en la provincia de Soria.

T. P., 1992, nº 49 


\section{HISTORIA DE LAS INVESTIGACIONES EN CARRATIERMES}

Los datos que se conocían de la necrópolis celtibérica de Tiermes eran confusos y la ubicación inexacta. Las primeras notificaciones que se tienen sobre el hallazgo de materiales celtibéricos en Tiermes, o atribuibles a procedencia cementerial, nos las facilitan diversos autores: el Conde de Romanones (1910), Ignacio Calvo (1913), Narciso Sentenach (1911, 1915), Juan Cabré (1917: 50-51), quien, en el apartado que titula Necrópolis ibérica de Termancia, en el tomo IV de su "Catálogo Monumental de Soria», manifiesta lo siguiente: «... en mi opinión todavía no se ha descubierto pues lo que (para) el Señor Sentenach lo es y existente a medio kilómetro en dirección Oriente del cerro y constituida por series de sepulturas excavadas en la roca de forma antropoide, opino que pertenece a otro pueblo más antiguo, quizás neolítico, o aquel pueblo que grabó en las peñas por todos los contornos de Tiermes y cuyas obras he expuesto y descrito ampliamente en el primer tomo de este catálogo ...». Por la descripción que hace este autor, las notas que señalan los detalles de situación se refieren a la necrópolis rupestre, que se halla junto al río Manzanares, y que no corresponde a una etapa cronológica anterior al pueblo celtíbero, sino que es más moderna (Argente Oliver, 1989: 88-90). A unos metros de las tumbas citadas, se ubica la necrópolis celtibérica de Carratiermes, en la que se llevan efectuadas varias campañas consecutivas, a partir de 1986.

Por último, Taracena resume en su «Carta Arqueológica de la Provincia de Soria» lo conocido sobre el tema, y destaca los objetos más significativos, refiriéndose a la relación de piezas que

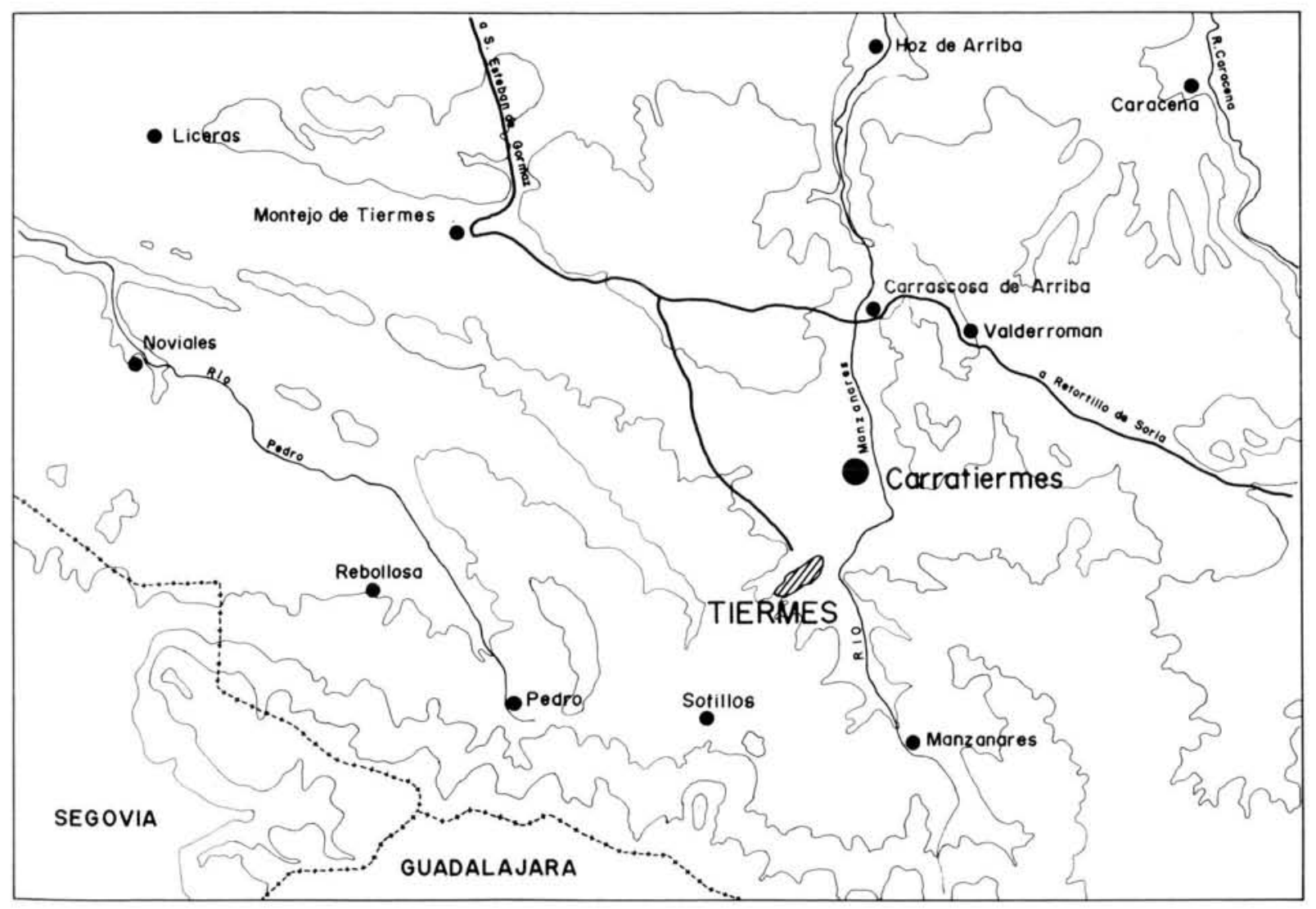

Fig. 2.-Carratiermes en su entorno geográfico. 
señalan autores precedentes, indicando al respecto lo siguiente «... este conjunto de hallazgos no autoriza a fecha más dilatada que entre el siglo IV-III y el año 97 antes de J. C.» (Taracena, 1941: 108); sin embargo, no hace mención al lugar que ocupa la necrópolis celtibérica.

Ya no existen más noticias sobre el tema hasta 1975-76, fecha en la que, el entonces guarda del yacimiento, D. Doroteo García Yagüe, recuperó diversos objetos de distintas parcelas en las que se extiende la necrópolis de Carratiermes, cuando se llevaban a cabo tareas agrícolas. Este suceso nos posibilitó realizar unos sondeos en el mes de abril de 1977, cuyos resultados no fueron todo lo satisfactorios que deseábamos, aunque, sin embargo, permitieron corroborar la existencia en aquel lugar del cementerio celtibérico de la Tiermes prerromana (Argente Oliver y Díaz Díaz, 1979). Poco tiempo después, se publicó un ajuar que presumiblemente procedía de Carratiermes y cuya composición responde a un momento avanzado de utilización de la necrópolis (Ruiz Zapatero y Núñez García, 1981).

A partir de este momento ya no hay otra información que incorpore datos sobre la necrópolis de Carratiermes, pues sólo las campañas de excavación, efectuadas desde 1986 hasta la fecha, constituyen la fuente que permite ir conociendo las características peculiares del cementerio.

Los trabajos de campo que se han efectuado en Tiermes, durante el período de 1975-1986 (Fig. 3), trataron de reconocer diversos aspectos de la ciudad romana (Argente Oliver y Díaz Díaz, 1990), dejando en segundo plano la investigación en Carratiermes; sin embargo, y debido al expolio realizado por clandestinos en 1985, trasladamos el centro de actividad de las campañas efectuadas entre 1986-1991 a este punto del yacimiento de Tiermes, recuperando una información muy importante, que se ha dado a conocer recientemente en diversos trabajos (Argente Oliver, Díaz Díaz y Bescós Corral, en prensa).

\section{CARACTERISTICAS DE LA FASE PROTOCELTIBERICA. DEFINICION DEL TERMINO}

Expuestos los datos generales sobre Carratiermes, vamos a referirnos ahora a la etapa de formación que culminará, a partir del siglo IV a. C., en el período que se conoce como Cultura Celtibérica Plena.

La fase protoceltibérica se corresponde con el primer Hierro en la zona, desde el momento de los influjos de los Campos de Urnas del Hierro del valle del Ebro hasta la celtiberización inicial, con la aparición, como elemento tecnológico fundamental, del torno. El término fue propuesto por primera vez por Ruiz Zapatero y Lorrio Alvarado (1982) para designar este grupo de necrópolis, refiriéndose a las antiguas del Alto Jalón. Términos análogos usados son principalmente los de necrópolis de Hallstatt (Aguilera y Gamboa, 1916) necrópolis posthallstátticas (Bosch Gimpera, 1921); Primer Hierro de la Meseta y sus inmediaciones (Cabre Aguiló; 1930: 30-33); periodo I de la cultura celtibérica (García-Soto Mateos, 1990). Casi el primero de estos términos es el de necrópolis posthallstátticas, que fue criticado por su inexactitud, ya al poco tiempo de su proposición (Cabré Aguiló, 1930: 32-33). Pretendemos demostrar la adecuación del término de protoceltibérico a la realidad arqueológica que se observa en la necrópolis celtibérica de Carratiermes.

Asimismo, últimamente se tiende a diferenciar la existencia de una fase de transición entre las dos edades clásicas del Hierro y en este sentido aparecen los términos de Cogotas IIa, cuando se quiere aplicar al Oriente de la Meseta (Martín Valls, 1986-87); protoarévaco (Romero Carnicero, 1982), en paralelo con el término protovacceo de Wattemberg (1959) y con el mismo sentido; o el período II de García-Soto Mateos (1990a). Sin embargo, este momento no está todavía lo suficientemente bien definido en la Meseta Oriental, ni siquiera en la amplia necrópolis de Carratiermes.

Los diferentes elementos de ajuar funerario de la fase protoceltibérica continuarán en gran medida en la fáse celtibérica — sobre todo al comienzo de la misma-, tal como lo hemos verificado en Carratiermes, pero tienen su origen en un momento claramente anterior. La continuidad parcial es perfectamente distinguible, tanto en Carratiermes como en otras necrópolis, caso de la de Ucero

T. P., 1992, n 49 


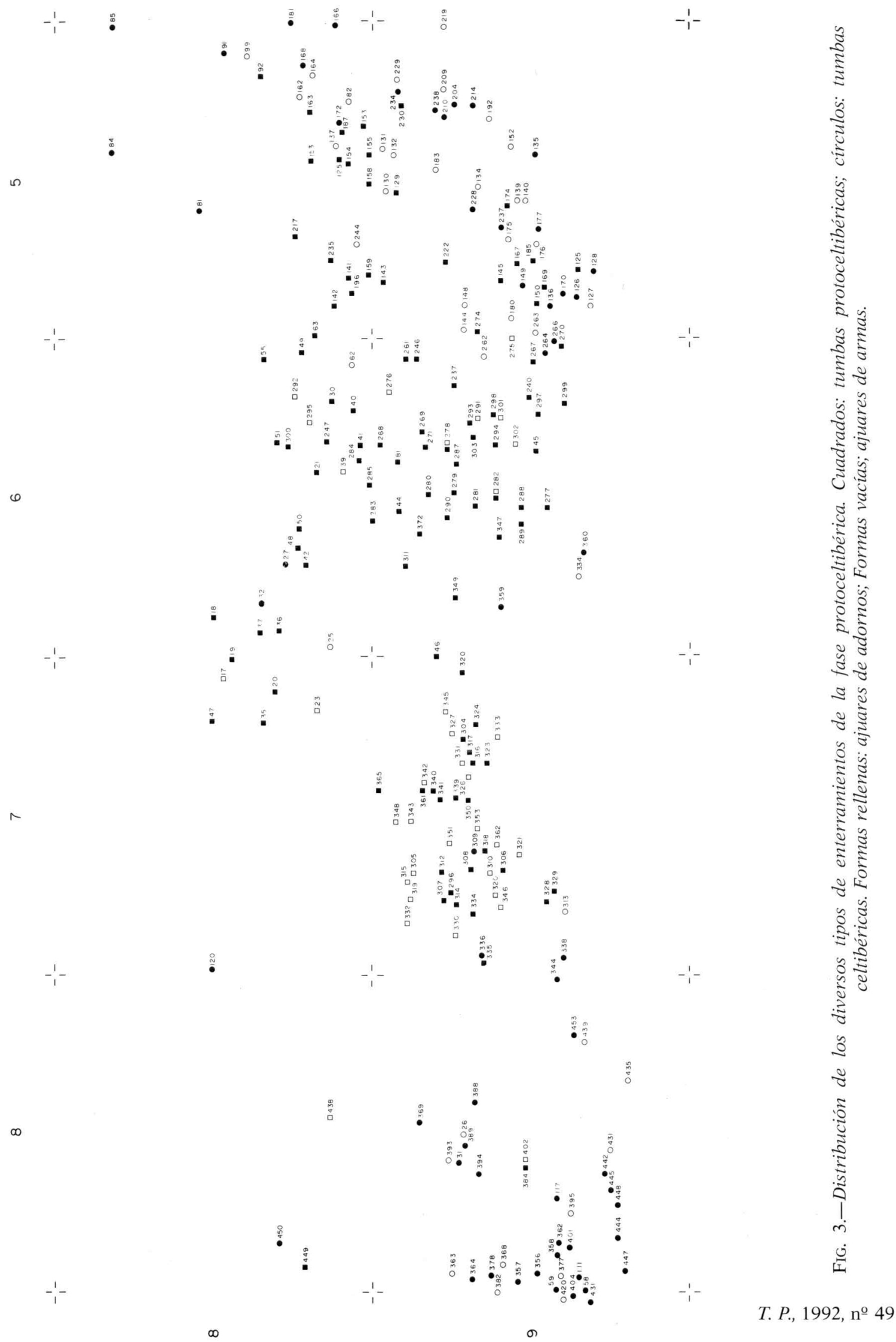


(García-Soto Mateos, 1981 y 1990a), por citar un yacimiento en curso de investigación y próximo geográficamente al nuestro.

Expuestas las notas precedentes, vamos a examinar a continuación los elementos materiales que configuran la fase protoceltibérica en Carratiermes, que pueden generalizarse a las demás necrópolis conocidas en el área, entre las que existen diferencias no sustantivas.

\section{MATERIALES PROPIOS O ADJUDICABLES A LA FASE PROTOCELTIBERICA}

Dada la continuidad material entre las fases protoceltibérica y celtibérica, es la concurrencia de los tipos iniciales en las tumbas lo que las define como pertenecientes a la fase protoceltibérica y permiten diferenciarla.

Hay también una serie de piezas exclusivas, cuya presencia indica claramente la adscripción de la tumba a la fase celtibérica; es el caso de las fíbulas de doble resorte de tipo 3D; las anulares hispánicas evolucionadas, tipos 6C y 6D; o los modelos de pie vuelto con torrecilla, las zoomorfas, tipos 8A2 y 8B1, entre otros (Argente Oliver, 1989: 118 y ss.; 154-188 y 217 y ss.); y sobre todo, la cerámica a torno, que nos facilita, en un ambiente de necrópolis, referencias a un cambio tecnológico importante, a diferencia del resto del material que nos lo ofrece simplemente desde el punto de vista morfológico.

La cerámica a peine, aunque no existe claramente delimitada en el horizonte protoarévaco (Romero Carnicero, 1984a y en prensa su última evaluación sobre el tema), sí parece indicar el momento de transición entre el final de la fase protoceltibérica y la celtibérica inicial, dado que se halla en conjuntos cerrados mayoritariamente con ausencia de cerámica a torno, y también en otros de datación celtibérica.

Expuestas estas ideas, pasamos a revisar los materiales representativos del momento cronológico que estudiamos, y cuya presencia en Carratiermes ha sido registrada en los inventarios.

\subsection{Cerámica}

Podemos hacer la división usual entre las formas de superficies pulidas y tamaño pequeño o medio y aquellas con tratamiento menos cuidado y mayor tamaño.

La forma de urna a mano casi exclusiva es el cuenco (Fig. 4, 1 y 2). Aparece en la mayoría de las necrópolis de esta zona, aunque en poca cantidad y a ella debe hacer referencia Aguilera y Gamboa cuando habla de un grupo de cerámicas de Aguilar de Anguita «... negras, y de un barro tan malísimo que se deshacían al sacarlas y es dificilísimo de reconstruir ..." (Aguilera y Gamboa, obra inédita; tomo III: 22).

$\mathrm{Su}$ variabilidad es grande, pudiendo ser desde de paredes rectas a convexas, con borde recto a reentrante. Sus bases pueden ser planas, ligeramente rehundidas o con umbos. En su totalidad, el tratamiento exterior es muy cuidado, pudiendo ser espatulado o bruñido en la pared externa, y que se continua, a veces, por parte de la interna, adquiriendo en una última fase de cocción un tono negro intenso y brillante. Las paredes - en la mayor parte de los casos- se van estrechando desde la base hasta el labio. La cocción es mayoritariamente de nervio de cocción, tanto oxidante como reductor, siendo escasa la cocción reductora e inexistente la oxidante en esta forma, apareciendo más frecuentemente la reductora en el momento más tardío. Los exteriores son negros u ocres muy oscuros; predomina el degrasante de mica blanca con algo de cuarzo. Son de tamaño pequeño (unos doce centímetros como altura máxima), con mayor diámetro de boca que altura.

La distribución de estas piezas en el tipo de yacimientos que nos ocupa es amplia, pero en el valle del Ebro y en lo que nos ha llegado de las formas cerámicas de las necrópolis antiguas, no parece ser la forma mayoritaria. En la necrópolis de Las Cogotas (Cabré Aguiló, 1932) sí aparece en tan gran cantidad como lo hace en Tiermes, aunque allí se halla frecuentemente asociada con la 

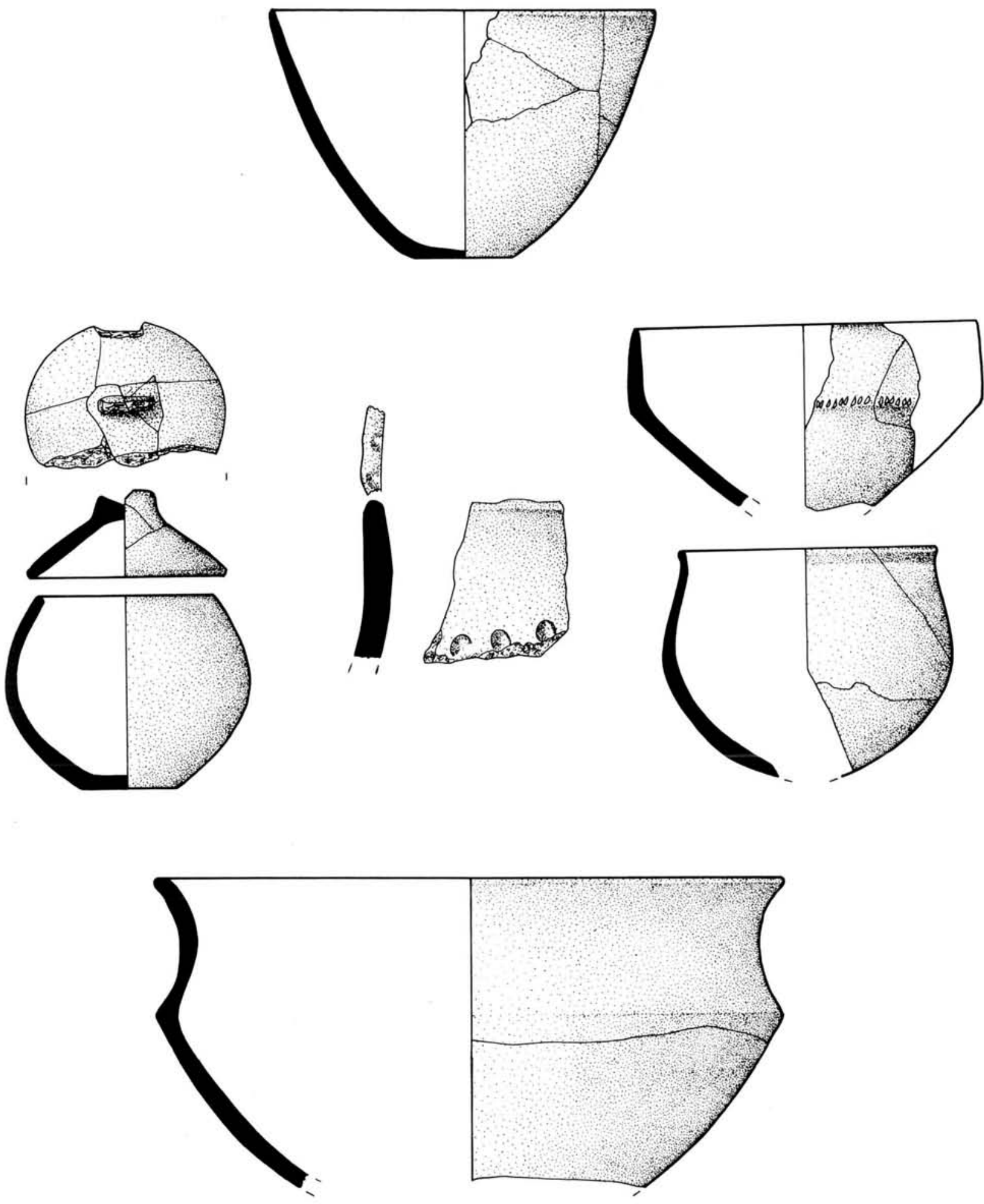

Fig. 4.-Formas cerámicas.

1. P., 1992, $\mathrm{n}^{\circ} 49$ 
decoración a peine, siendo mucho menos frecuente ésto en Carratiermes. Respecto a la cronología de estas piezas, en la necrópolis de Luzaga (Díaz Díaz, 1976: 468-477) no aparecen las cerámicas de paredes abiertas y base plana y en la de La Atalaya (la necrópolis de Cortes de Navarra) (Maluquer de Motes, 1957) el cuenco se presenta siempre con bases planas o ligeramente rehundidas. Dado que el yacimiento de Luzaga tiene una cronologia clara a partir del s. IV a. C. -incluso mediada dicha centuria- y el de La Atalaya termina con la aparición de la cerámica a torno en la zona (a mediados del IV a. C.), las formas de cuenco de bases planas pueden corresponder a la fase protoceltibérica para esta zona. De todos modos, la sencillez del modelo hace probable su pervivencia en la fase celtibérica. Formas troncocónicas y de tendencia hemiesférica aparecen asociadas en Las Madrigueras (Almagro Gorbea, 1969: 107, lám. XIX) a los estratos IV y III, con una cronología del s. VI, todo el V y principios del IV a. C., y en Navarra (Castiella, 1977) pertenece a la forma 7, que se corresponde con el cuenco genérico, con una cronología muy amplia, alcanzando la segunda Edad de Hierro. Podríamos suponer pues, para esta forma sin decoración, una cronología con límite de mediados del IV a. C., sin poder descartar pervivencias.

El resto de las formas aparecen en mucha menor cantidad y pocas veces en contexto de tumba.

Entre ellas, podemos citar el cuenco de borde cilíndrico y paredes troncocónicas, que se puede paralelizar con la forma 3 de Romero (1984b), que en Carratiermes presenta una serie de trazos incisos oblícuos en la carena (Fig. 4, 3).

La forma de cuenco de paredes convexas y labio levemente exvasado se relaciona con la cerámica de Soto II de Pago de Gorrita (Valladolid) y aparece también en Roa (Burgos), pero más directamente con la forma 2 de la Cultura de los Castros (Fig. 4, 4; Romero Carnicero, 1980: 146, fig. 2, 5 e ID. 1984, fig. 2, 2 y nota 114, Sacristán de Lama, 1980).
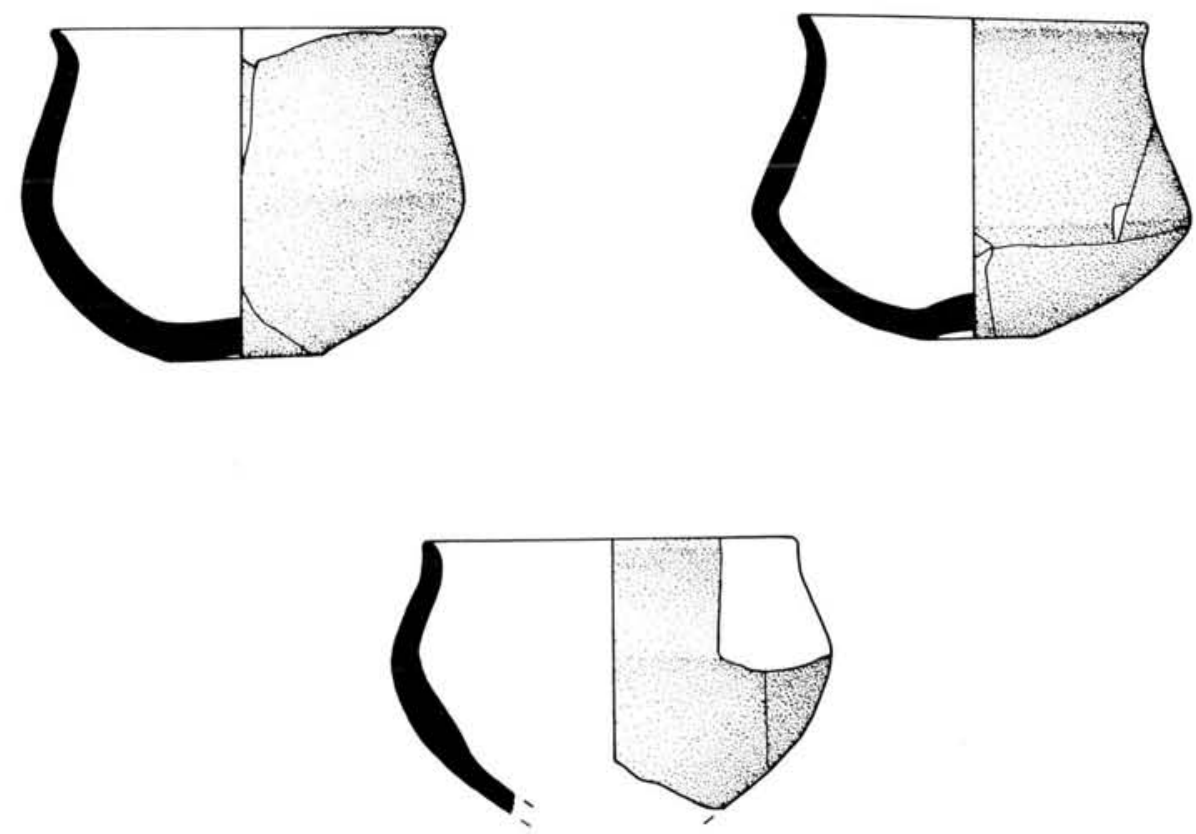

Fig. 5.-Formas cerámicas.

T. P., 1992, no 49 
La $\mathrm{n}^{\circ} 6$ (Fig. 4), inventariada en la tumba 272, es un cuenco oxidante de forma cóncavo-convexa de gran diámetro que corresponde a esta fase por el ajuar de pectoral de espirales y collar de cuentas que posee.

Las formas sin pulir son escasas, debido al caracter ritual del material en la necrópolis; aparecen restos de formas de bordes cóncavos de tratamiento, como mucho, alisado, con degrasante medio y grueso, de cuarzo y cocción reductora con exterior ocre claro (Fig. 4, 6). Estas piezas presentan frecuentemente bandas de trazos oblícuos y cordones digitados o de trazos incisos. Los fragmentos que poseemos se pueden relacionar con la forma I de Castiella (1977) dentro de su grupo de las cerámicas sin pulir.

\subsection{Objetos en metal}

En el inventario de piezas metálicas que se puede establecer en los ajuares protoceltibéricos de Carratiermes destacan, entre otros, ciertos elementos importantes, tanto por sus características morfológicas como cronológicas; es el caso de las fíbulas, broches de cinturón y pectorales. Van a ser ellos los que permitan obtener la información que nos facilita establecer unas bases para la mejor comprensión de la etapa protoceltibérica.

\subsection{A. Fíbulas}

Es uno de los objetos más frecuentes en las necrópolis de nuestro estudio; por su relevancia como elemento de estatus personal, unido a su sensibilidad tipológica para el cambio cronológico y cultural, ha sido considerado desde siempre de la mayor importancia para la clasificación y datación temporal de los conjuntos y yacimientos en donde aparece. En este sentido, y una vez que revisemos las piezas inventariadas en Carratiermes como correspondientes a la fase protoceltibérica, comprobaremos que las fíbulas aportan una información de suma importancia, en orden a la datación de los conjuntos que clasificamos en la fase que ahora estudiamos.

En el inventario de fíbulas de Carratiermes, las que incluimos en la etapa protoceltibérica ofrecen una variedad importante de modelos y tipos, todos ellos pertenecientes a un período cronológico similar. En los ajuares de dicha necrópolis, suelen existir uno, dos, tres y hasta cuatro de estos objetos. Los modelos a los que corresponden son: sin resorte; doble resorte, tipos 3B y 3C; anular hispánica, tipo 6B (Fig. 13, 5041); pie vuelto, tipos 7A (Fig. 10, 3936) y 7B (Fig. 12, 1991); de espirales, tipo 9A2 (Argente Oliver, 1989). Todos se datan entre fines del siglo VI a. C. y la centuria siguiente, a excepción de uno de los tipos, el 6B, que tiene una cronología muy amplia, pues abarca hasta el siglo I d. C.; sin embargo, las piezas que ahora se incluyen no ofrecen dudas en cuanto a su adscripción, a un primer momento de fabricación del tipo.

Lo expresado es válido tanto para los ajuares de adornos como para los de armas; en ambos, se registran los mismos modelos de fíbulas y broches de cinturón - como luego veremos-, piezas que siempre suelen aparecer relacionadas en los ajuares, tal como se ha indicado en estudios precedentes.

\subsection{B. Broches de cinturón}

En la necrópolis de Carratiermes contamos con un nutrido número de ejemplares de este tipo de piezas, ofreciéndonos el dato de que tan sólo son frecuentes en el período protoceltibérico, hallándose prácticamente ausentes los tipos de broches de cinturón con datación en la etapa celtibérica plena, tal como se ha puesto de relieve en un estudio reciente (Alonso Lubias, en prensa).

La mayoría de los ejemplares de Carratiermes pertenecen a la producción denominada "céltica", y los tipos registrados son los de uno y tres garfios, con escotaduras cerradas (Figs. 8, 1986; 10, $3931 ; 11,2386 ; 13,5040$ ), encontrándose ausentes' los denominados "prototipos" (de los que se

T. $P ., 1992, \mathrm{n}^{2} 49$ 
conocen algunas piezas en la zona de nuestro estudio), los broches con escotaduras laterales cerradas y algunas variantes de los de escotaduras laterales abiertas. El número más importante queda enmarcado en el tipo D-III de Cerdeño, tanto en sus variantes de un garfio como de tres, conociendo un sólo ejemplar de cuatro garfios y ninguno de dos (menos frecuentes) (Cerdeño Serrano, 1978).

Por lo que respecta a las hembras, se registran dos tipos: el serpentiforme (Figs. 13, 5040; 7 , $11140 ; 8,1986 ; 10,3987 ; 11,2387)$, junto a las piezas machos de tres garfios, y el rectangular, correspondientes a los de un sólo gancho.

En cuanto a la técnica decorativa, los broches de cinturón de Carratiermes tienen características similares a los inventariados en la Meseta Norte, con motivos incisos y sucesión de puntos en relieve o granetti, desarrollados a lo largo del contorno de la pieza y en su parte central, nunca en los garfios, por lo que respecta a las piezas machos; en cuanto a las hembras, en los casos en que aparece (los de tipo rectangular), la decoración es similar.

Del total de piezas inventariadas en Carratiermes, una buena parte se hallaron en ajuares conservados in situ, mientras que otro lote, no tan importante numéricamente, se encontraba fuera de su contexto inicial.

En la figura 14, se observa, en la relación de objetos por tumbas, cómo los broches de cinturón se catalogan tanto en los ajuares de guerrero como en los de adornos de bronce, a la vez que en todos ellos existen pectorales o restos de los mismos; en este mismo sentido, aunque hay un mayor número total de fíbulas, siempre suelen coincidir éstas en aquellos mobiliarios en los que se inventarían broches de cinturón.

En el recuento de los ajuares que relacionamos en la figura 14 , se deduce que el $38 \%$ de los ajuares de guerrero poseen en su inventario broches de cinturón, mientras que en los de piezas de bronce se eleva al $62 \%$; lógicamente estos porcentajes hay que tomarlos con la necesaria precaución que implica el tamaño de la muestra, además de encontrarse la necrópolis todavía en proceso de excavación, pero que entendemos resultan claramente significativos. Es muy posible que los porcentajes establecidos varíen en el estudio final de la necrópolis, estableciéndose una relación bastante más igualitaria entre ambos grupos.

\subsection{Pectorales}

Dentro de los conjuntos de adornos, destacan por su naturaleza, conservación y precisa identificación las piezas que denominamos "pectorales", y de los que hasta el presente solamente se conocian algunos ejemplares aislados y/o piezas sueltas de los mismos, pero que, a juzgar por los restos hallados en Carratiermes, debieron ser relativamente frecuentes en el mundo celtibérico, dependiendo siempre de la importancia social que alcanzó el individuo propietario de estas piezas. El término fue ya utilizado al estudiar algunos conjuntos de las necrópolis de Alpanseque (Cabré de Morán y Morán Cabré, 1975; Fernández Galiano y Valiente Malla, 1982; García-Soto, 1990b; Schüle, 1969).

Además, consideramos a estos objetos de sumo interés, pues resultan ser una de las expresiones más características de la etapa protoceltibérica; se trata de elementos que pertenecen claramente a la etapa de plenitud, dentro de lo que se considera previo al mundo celtibérico, aunque algunas piezas lleguen a estar presentes con cerámicas a torno, particularidad que indica ya la fase celtibérica plena, pudiendo datar entonces ciertos pectorales en una cronología más moderna (Argente Oliver, Díaz Díaz, y Bescós Corral, en prensa; García Soto-Mateos, 1990b).

En estos objetos se pueden distinguir diversos modelos, que han podido ser identificados tanto por los hallazgos de Carratiermes como por los ejemplos, aunque no tan completos, de diferentes yacimientos, principalmente aquéllos que se integran en la llamada "Colección Cerralbo"; por otro lado, la distinciốn que hacemos se relaciona con los ejemplares identificados en diferentes áreas de Europa. Los tipos que señalaremos a continuación son distintos, incluso, según estimamos, en cuanto a su funcionalidad.

T. P., 1992, n² 49 
Los modelos que se advierten son dos: los constituidos por placas, ya sean circulares o rectangulares, y los espiraliformes, realizados con alambres de bronce, que rematan en espirales a lo largo del vástago central en que se desarrollan. En el primer caso, se suelen añadir otros elementos metálicos que completan la ornamentación de la pieza resultante.

Así, pues, y teniendo en cuenta lo dicho, distinguimos dos modelos, que son generalizables a toda la zona celtibérica:

Pectorales de espirales. El objeto consta de cinco piezas: el vástago, las espirales, la aguja, los colgantes helicoidales y los de anteojos. El primero consiste en un alambre enrollado sobre una varilla de bronce o -en escasos ejemplares- de hierro. Junto a la varilla se disponen los extremos laminares de las espirales que así quedan fijadas por el arrollamiento general del eje. Las espirales varían de 4 a 12 con una disposición tendente a la simetría sobre y bajo el vástago. De las espirales de la línea inferior penden, por medio de colgantes helicoidales (de 6 a 8 por cada espiral), unas espirales dobles («anteojos»). Por último, la aguja es de sección circular salvo uno de sus extremos que se aplana para enrollarlo en el centro del vástago (Fig. 9).

Por lo que respecta al origen de los pectorales de espirales, Cabré-Morán (1975) estiman que, para las fíbulas de espirales, las representaciones más antiguas se hallan en Oriente, en los alfileres tetralobulados, realizados en hilo de oro y procedentes de la Troya del III milenio (Cabre-Morán, 1975). De alli pasarían a Grecia y luego al Mediterráneo, llegando hasta Italia y Europa Central. Schüle los relaciona de un modo más directo con las fíbulas de tipo Posementerie, de la fase Ha B2 (Müller-Karpe, 1959), con una cronología entre el 900 y el 850-750 a. C. Sin embargo, este tipo no se extiende más allá de la zona comprendida entre el Báltico y el Mar Negro (Gimbutas, 1965). Así las cosas, los predecesores más cercanos a nuestras fíbulas de espirales corresponderían a la cultura del período hallstáttico y al vilanoviano. Es lo más probable que los pectorales de nuestra Meseta Oriental sean una evolución de la fíbula de espirales, ampliamente extendida por Italia, encontrándose bien representada, en el tipo de vástago con 4 espirales, en la necrópolis de Este, y que son asignadas de un modo general a la fase II (Ha B3), con una cronología entre el 800 y el 700 a. C. (Peroni et alii, 1968). Este sería el modelo del tipo de fíbula de espirales 9.A.2 de la Meseta Oriental (Argente Oliver, 1989: 236-249).

Pectorales de placa. Son aquellos que se constituyen a partir de una placa de bronce; a ella se le añaden diferentes complementos, tanto por encima como por debajo de la misma (Fig. 6; Lám. 1).

En cuanto al modelo, se puede generalizar que se componen de tres partes: la central, que es la placa rectangular en sí, mientras que la superior e inferior llevan los elementos complementarios de adorno de la pieza, que son sencillas campanillas (la inferior) y una placa recortada (la superior) en la que se ejecutan dos círculos o bien se sustituyen por otras tantas espirales. La placa recortada se sujeta a la parte central por medio de dos remaches, mientras que las espirales lo hacen con un pequeño y fino alambre. En el centro de la parte superior del pectoral se coloca la aguja, que permite sujetar la pieza en el soporte correspondiente.

Aún es posible añadir un tercer tipo, que se distingue porque la parte superior, unida la placa rectangular, es simplemente una plancha que se dobla para su sujeción en la prenda correspondiente.

A los modelos de placa de la Celtiberia, Schüle les atribuye un nacimiento itálico (Schüle, 1969: 111 y mapas 31 y 32), siendo el paralelo más próximo los pectorales de la cultura Picena, en la costa adriática en el centro de la península italiana, con una cronología del s. VIII (I Edad del Hierro). Hay que señalar que los modelos picenos, siendo los más parecidos a los nuestros, son exclusivos de su zona, no registrándose en el resto de la Península Itálica (Trump, 1966).

El camino de introducción, para el modelo particular, es poco claro, ya que no aparecen los modelos de placa más que en la zona celtibérica de Soria y Guadalajara. Puede ser por el valle del Ebro, donde se documentan, y aparecen los colgantes cónicos ("campanillas") y los colgantes helicoidales: pequeños vástagos recubiertos de alambre en la necrópolis de Can Canyis (Período IV de Vilaseca) (Vilaseca Anguera, 1963) aunque allí se registran como partes de collares en los que ellos son los elementos principales. Se dan también los colgantes cónicos y las cadenillas en la necrópolis castellonense de Solivella (Fletcher Valls, 1965) donde parecen corresponder a collares más que a un pectoral.

T. P., 1992, $\mathrm{n}^{2} 49$ 


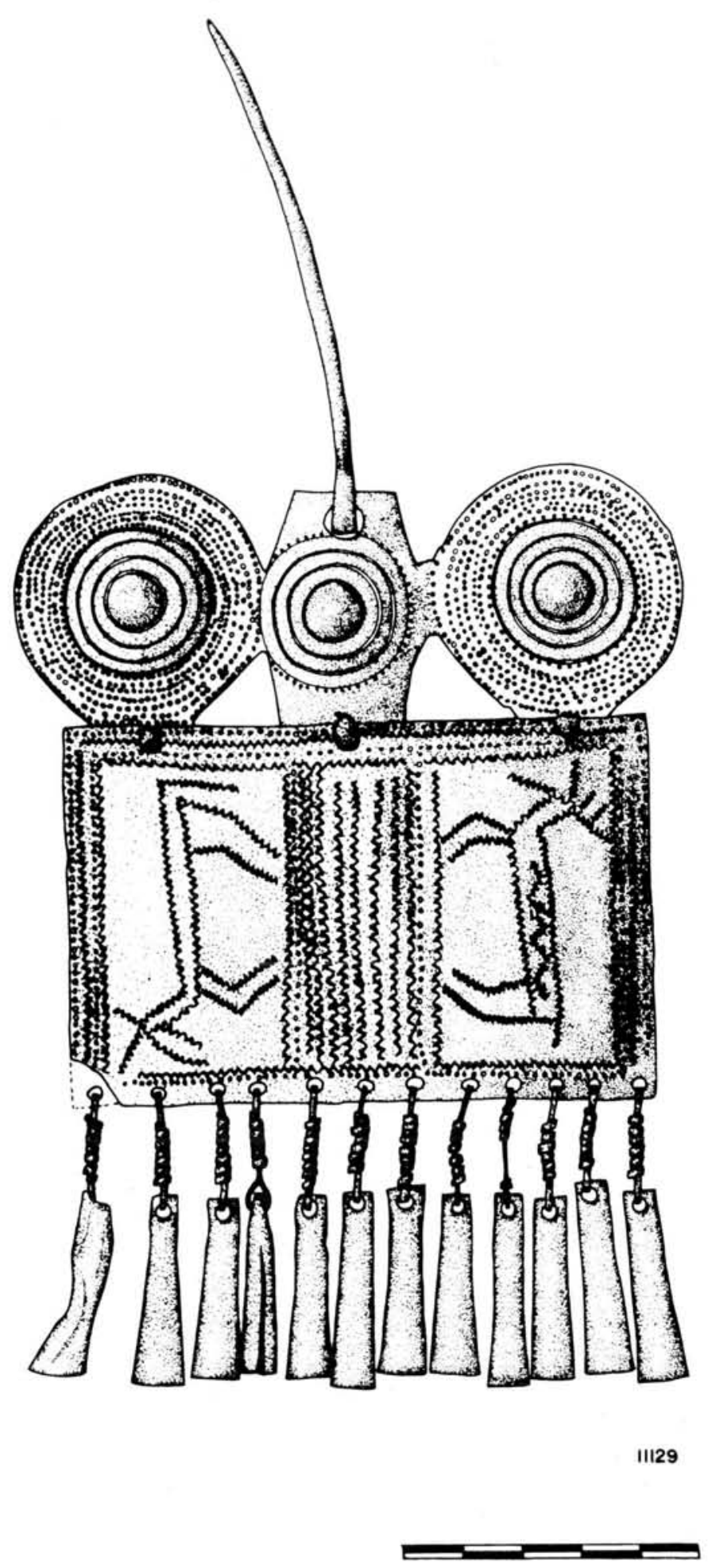

FIG. 6.-Pectoral de placa de la tumba 235.

T. $P ., 1992, \mathrm{n}^{\circ} 49$ 

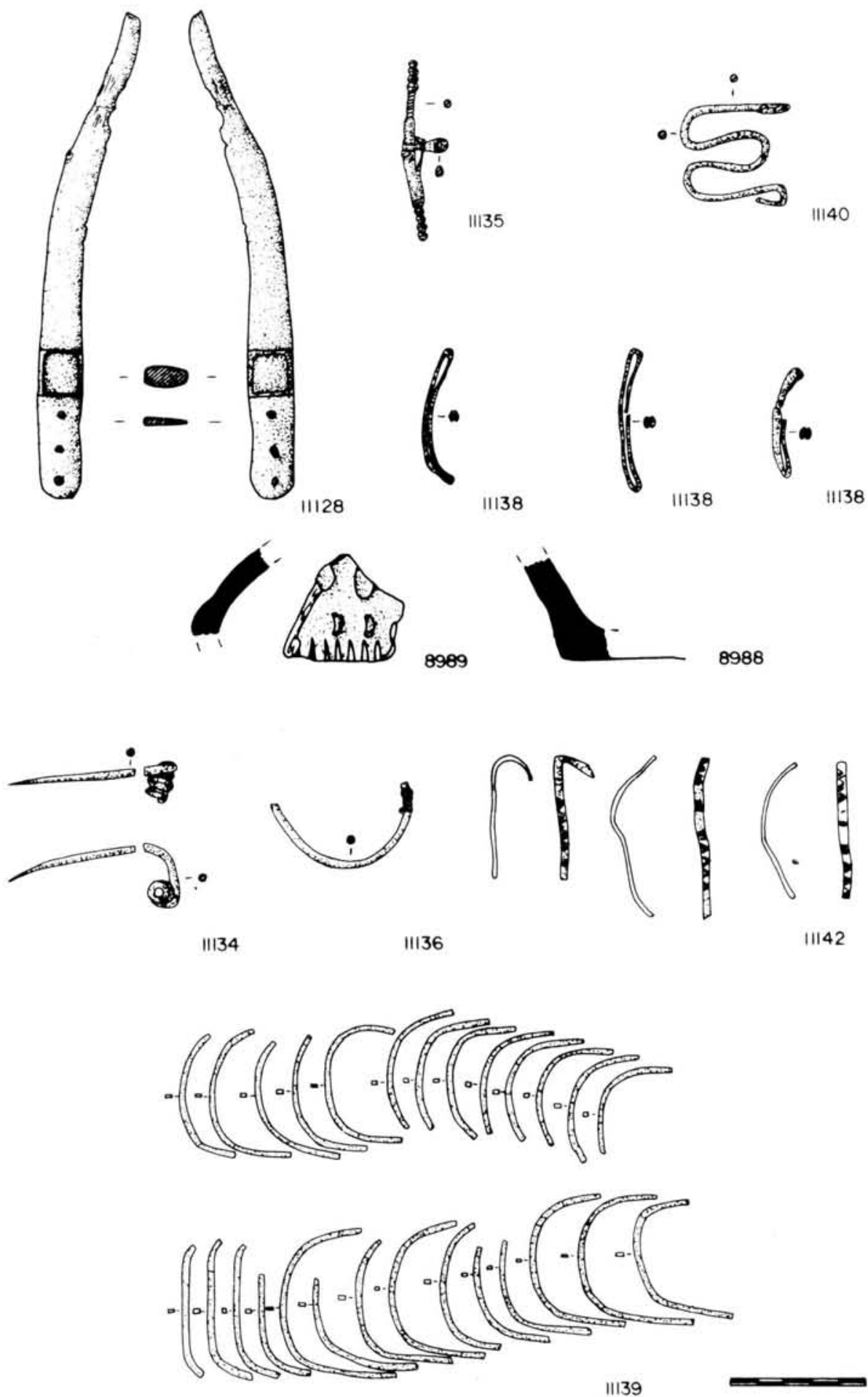

FiG. 7.-Ajuar de la tumba 235.

T. P., 1992, no 49 
Respecto al significado de estas piezas podemos ver que entre las piezas del Museo de Ascoli encontramos pectorales de placa con una representación, en la parte superior, de una diosa con caballos y, colgando de la placa en sí, representaciones humanas esquemáticas (Randall, Mc Iver, 1927) de modo que podríamos atribuirle un significado religioso a estas piezas, aparte de su función de diferenciación social.

Este tipo de piezas se podría poner en relación con los colgantes de cadenillas, los cuales aparecen asociados a las placas en la zona Picena y, en nuestra zona, en la necrópolis de Clares y en la de Torresabiñán, con una cronología del s. IV. Los distintos elementos que forman el adorno, los colgantes helicoidales y las espirales se presentan asociados a distintos elementos sustentantes: fíbulas, láminas de bronce, placas o cadenas; también aparecen asociados entre sí y a otros tipos de colgantes, como cadenillas, aros simples o geminados y vástagos. Se trataría así de una serie de elementos de adorno femenino, los cuales se conjugarian en distintas asociaciones, cambiándose campanillas por cadenas o por vástagos helicoidales. De este modo la correspondencia entre las placas de pectoral de la zona picena y las celtibéricas, podría ser una relación casual dentro de un adorno polimórfico. Lo contrario, la coherencia formal entre ambas zonas (también posible) implicaría una ilación directa entre el pueblo comercial de la costa adriática (los picenos) y la costa española.

\subsection{Armas y arreos}

Hay una ausencia de espadas o puñales, siendo características las lanzas, por lo común bastante largas, de nervio muy marcado en ángulo respecto al plano de la hoja, sea el nervio plano (Fig. 12, 5028) o curvo (Fig. 11, 3933); los filos son rectos y el entronque del filo con el mango en ángulo recto y esquinas redondeadas. Este tipo de lanzas no existen en la necrópolis de Las Cogotas, donde aparecen los tipos que en Tiermes se corresponden con los inicios de la fase celtibérica y la celtibérica: las lanceoladas de nervio en arista o las de sección rómbica; y tampoco aparecen en la más antigua de Chamartín de la Sierra. En la necrópolis de Altillo de Cerropozo las lanzas de nervio circular corresponden a los ajuares antiguos, luego se mezclan con las de sección rómbica, y el final de la evolución (con las espadas) se da en las lanzas de nervio en arista. La longitud de este tipo de lanzas señala hacia tipos más antiguos, así como su nervio resaltado, que luego tiende a difuminarse en las lanzas de nervio en arista o en las de sección rómbica.

Los escasos arreos son de los tipos más sencillos de arandelas y los escudos no poseen nunca umbo metálico (Fig. 10, 2384 y lám. 3; Fig. 13, 5036; Fig. 10, 2381), conservándose tan solo los agarres del asa. Las espadas, al menos en Carratiermes, parecen corresponder a la parte inicial celtibérica o final de la protoceltibérica, sin que ello niegue que en otras partes, como afirma CabréMorán, puedan iniciarse en el s. V.

\section{ASOCIACION DE MATERIALES. DESCRIPCION DE LOS AJUARES PROTOCELTIBERICOS}

Expuestos los materiales más significativos que corresponden a la fase protoceltibérica, por lo que a Carratiermes se refiere, vamos a expresar la asociación que existe entre los mismos, y para ello nos basamos en los ajuares excavados.

AJUAR DE ADORNOS DE BRONCE. Estos conjuntos suelen estar formados por unas piezas características: fíbula, broche de cinturón, pectoral, pulsera, collares de cuentas de pasta vítrea y, como único objeto fabricado en hierro, un cuchillo de hoja curva, entendido como una pieza multifuncional, pero nunca considerado exclusivamente como arma, aunque en casos extremos pueda ser utilizada como tal.

T. $P ., 1992, \mathrm{n}^{2} 49$ 


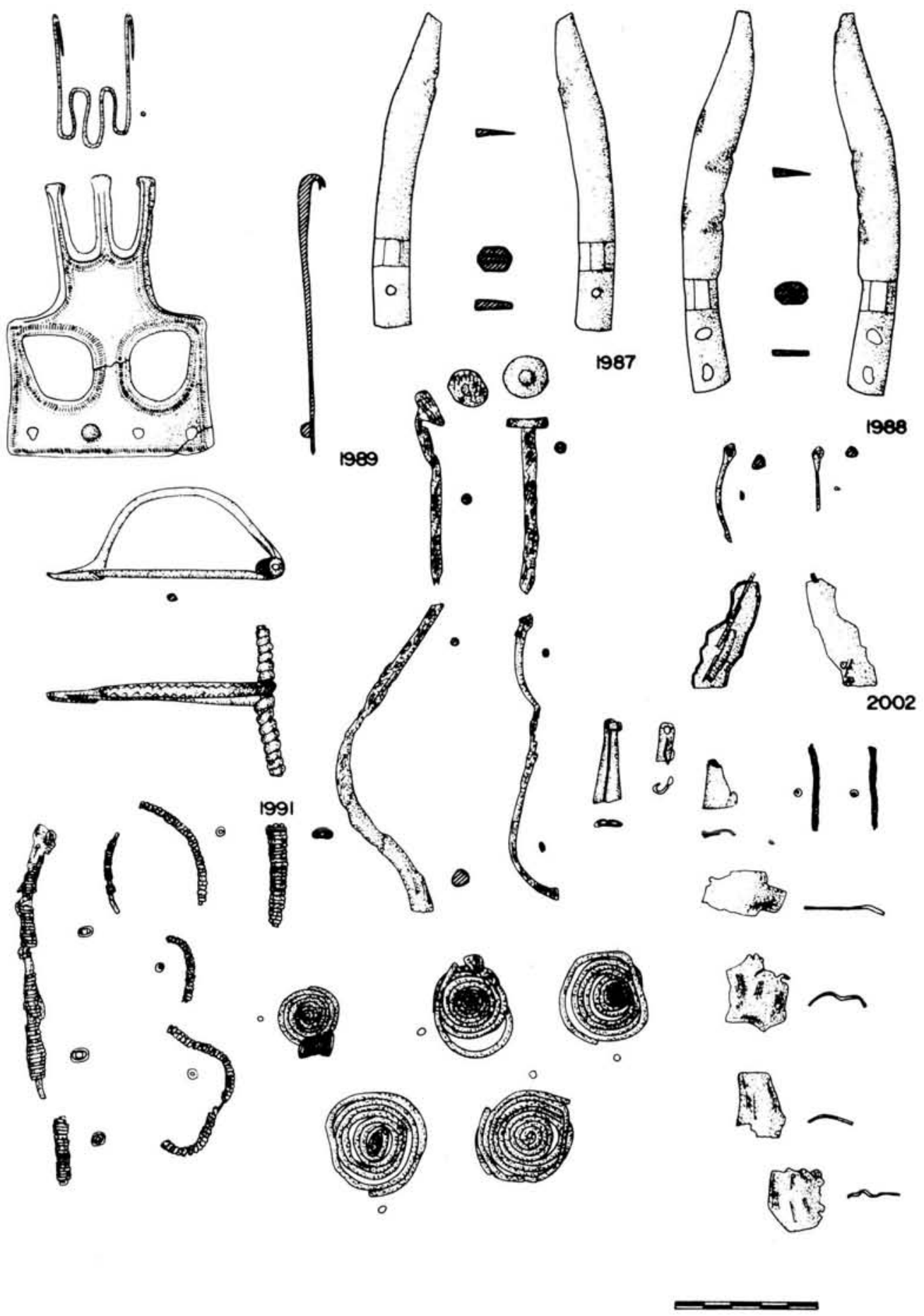

FIG. 8.-Ajuar de la tumba 291.

T. P., 1992, $\mathrm{n}^{\circ} 49$ 
De todas las piezas que componen estos ajuares, contamos con el apoyo cronológico de dos, que últimamente han sido estudiados en profundidad; nos referimos a los broches de cinturón (Cerdeño Serrano, 1978) y las fíbulas (Argente Oliver, 1974 y 1989). Un tercer objeto, el pectoral, constituye, aun no contando para él con datos cronológicos como en los casos anteriores, otro elemento diferenciador de los individuos que conformaron esta sociedad y que caracteriza a los ajuares de bronce de la etapa que denominamos protoceltibérica. Más adelante examinaremos la datación que ofrecen las piezas señaladas, permitiendo dicha circunstancia señalar las fechas en las que pueden situarse los conjuntos.

Los objetos relacionados ofrecen una unidad de conjunto que les distingue frente a otros ajuares de la misma o parecida datación hallados en la necrópolis; ésto identifica, a la vez, una categoría social y económica, pues viene a ser, por un lado, la representación de miembros de una condición social elevada y, por otro, una posición económica fuerte, ya que todos los objetos que se inventarían señalan una situación de poder frente a la mayoría de su sociedad.

AJUAR DE ARMAS. Las tumbas con ajuar de bronce se disponen junto a otras que, gozando de la misma datación que proponemos, presentan un sentido diferente y corresponde, a juzgar por los objetos inventariados en ellas, a individuos del estamento de guerreros; no obstante, las piezas recuperadas señalan ciertas diferencias con los ajuares de la élite militar de fechas posteriores.

En el estado actual de la investigación, el mobiliario del guerrero protoceltibérico se caracteriza por presentar, como norma general, las siguientes piezas: puntas de lanza de gran tamaño - suelen sobrepasar los 50 y $60 \mathrm{cms}$. de longitud total-, con fuerte nervadura central; regatones, con tamaño en relación a las puntas de lanza; en ciertos casos, bocados de caballo; cuchillo de hoja curva; fíbula, de bronce o hierro, (en este último material serán menos frecuentes en etapas posteriores); broches de cinturón, en su mayoría de tres garfios y escotaduras cerradas, del tipo D.III.3 de la tipología de Cerdeño (Cerdeño Serrano, 1978), aunque también se han inventariado broches de un sólo garfio y escotaduras cerradas.

Por lo que respecta a otro tipo de armas, caso de las espadas o puñales, hay que decir que no son características de la fase protoceltibérica, sino que corresponden a las siguientes centurias, dentro ya del mundo celtibérico pleno. Esta circunstancia se revela claramente en Carratiermes.

Algunos conjuntos presentan piezas poco frecuentes, como es el caso de calderos de bronce, que se encuentran aplastados con clara intencionalidad, y que se registran, en el inventario actual, en dos tumbas - números 321 y 327- o un cazo de bronce -tumba núm. 362-, lo que permite pensar, si el porcentaje se mantiene en trabajos futuros, en una importación de piezas de origen más lejano que las registradas más frecuentemente en los ajuares ya excavados.

Frente a estos mobiliarios ricos aparecen toda una serie de ajuares más pobres, que con frecuencia plantean dudas en la adscripción cronológica, caso de los que sólo presentan la urna de tipo de cuenco que posee una gran pervivencia.

\section{EJEMPLOS DE AJUARES METALICOS PROTOCELTIBERICOS EN LA NECROPOLIS DE CARRATIERMES}

Diversos ejemplos podrían traerse a colación entre los ya excavados en Carratiermes; sin embargo, hemos elegido cinco de ellos que permitan ofrecer las características de los dos tipos establecidos - de guerrero y de individuo civil- y que sirvan de modelo para trabajos futuros en el área de la Celtiberia estricta.

Ajuar de bronce. Presentamos los ajuares que identificamos con los números 235 y 291; ambos son dos exponentes precisos de las características reseñadas para este tipo de ajuares.

Tumba 235 (Figs. 6, 7, 8 y 9 y Lám. I). La estructura funeraria en donde se localizó el ajuar era de hoyo realizado en el nivel III -correspondiente al conglomerado natural en matriz arenosa-. Encima del hoyo quedaban restos de la cobertera pétrea que cubría la concavidad o pozo; la tierra alrededor de la estructura era negra. El ajuar inventariado consta de las siguientes piezas: 
- Pectoral de placa.

- Restos de pectoral espiraliforme.

- Fíbula de doble resorte, tipo 3C Argente.

- Anillo de fíbula anular hispánica.

- Fíbula de pie vuelto, tipo 7B Argente

- Hembra de broche de cinturón, tipo serpentiforme.

- Tres pasadores de bronce para sujeción del broche de cinturón.

- Fragmentos de pulseras de bronce, algunos con decoración incisa en una de sus caras.

- Cuentas de collar de pasta vítrea, color amarillo, muy deterioradas por acción del fuego.

- Cuchillo de hoja curva, de hierro.

No se inventarió urna; tan sólo algunos fragmentos de cerámica oxidante y reductora se hallaron en la parte superior del hoyo y entre la cobertera pétrea.

Tumba 291 (Fig. 8 y 9; Lám. II). Se encontró en un hoyo-rebaje, encima del cual había una cobertera de piedras, con una pequeña capa de pizarras. No se registró vasija alguna, así como tampoco estela ni restos óseos. Consta de las siguientes piezas:

- Pectoral espiraliforme completo.

- Restos de un segundo pectoral espiraliforme.

- Fragmentos de pectoral de placa; conserva alguna de las campanillas que completan la pieza.

- Fíbula de pie vuelto, tipo 7B Argente.

- Broche de cinturón, de tres garfios y escotaduras cerradas.

- Hembra de broche de cinturón, tipo serpentiforme.

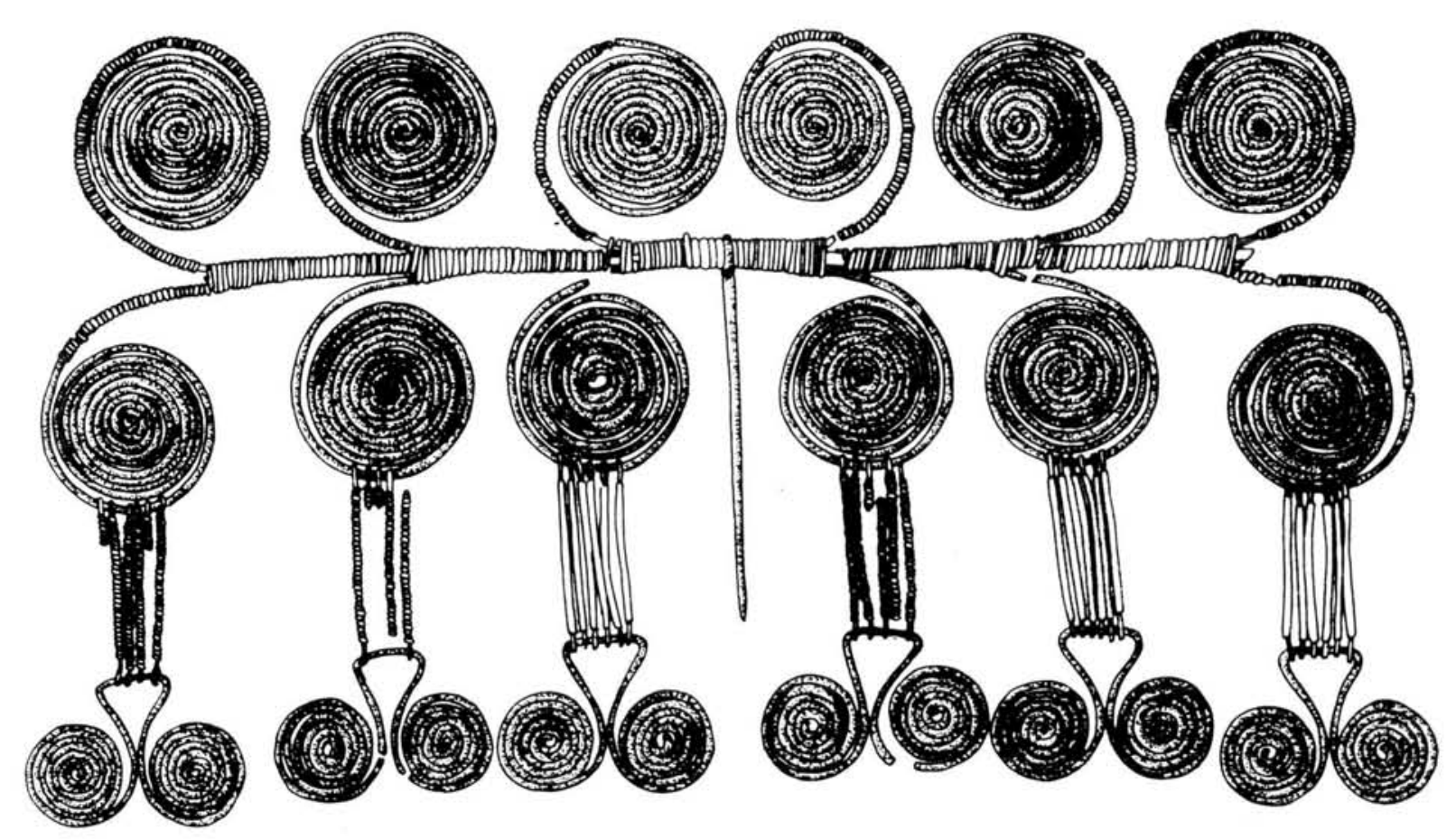

FIG. 9.-Pectoral espiraliforme de la tumba 291. 

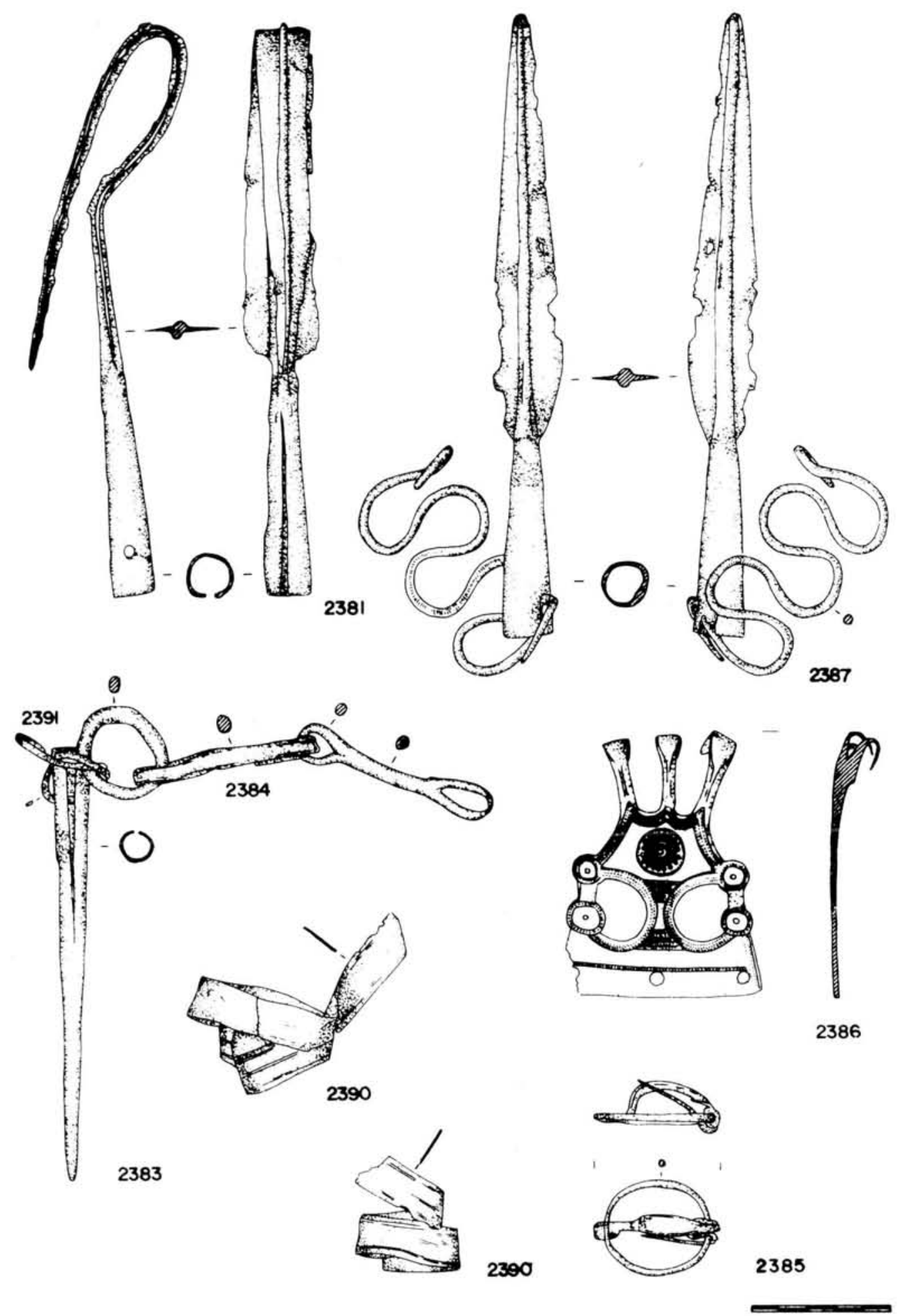

FIG. 10.-Ajuar de armas de la tumba 302.

T. P., 1992, nº 49 
- Collar completo de pequeñas cuentas de bronce, con un total de 2.247 piezas, con una longitud total que se aproxima a los 3,5 metros.

- Restos de cuentas de collar de pasta vítrea.

- Dos cuchillos de hoja curva, de hierro.

- Restos metálicos, sin poder indicar función concreta.

Mobiliarios de guerrero. En este apartado señalamos tres conjuntos —números 302, 319 y 327 del inventario general de tumbas de Carratiermes-, que recogen la idea del ajuar de guerrero, y en los que se identifican los objetos propios de esta época caracterizándose, como ya se ha dicho, por la ausencia de espadas, puñales y otras armas, que identifican otros momentos cronológicos del mundo celtibérico.

Tumba 302 (Fig. 10; Lám. III). Corresponde al tipo de estructura que denominamos de rebaje poco profundo, sin llegar a ser hoyo; rompe también el III nivel de la necrópolis, constituido por el conglomerado natural de matriz arenosa. Pertenece a la variante con cobertera pétrea, ya que, aunque no se encontraba in situ, existían restos de la misma alrededor del rebaje. El conjunto de las piezas estaba unido por una fina lámina de bronce. No se halló restos de vasija cerámica ni de estela pétrea; sí, en cambio, quedaban los restos óseos incinerados. El inventario de objetos es el siguiente:

- Broche de cinturón de tres garfios con escotaduras cerradas.

- Hembra de broche de cinturón, tipo serpentiforme.

- Dos puntas de lanza de hierro.

- Un regatón de hierro.

- Restos de un bocado de caballo.

- Lámina de bronce, de sección muy fina y forma rectangular alargada.

- Fragmento de varilla de bronce, de sección circular.

Tumba 319 (Fig. 10). La estructura del enterramiento es un hoyo realizado en el conglomerado natural; el ajuar se depositó en dirección norte-sur, y se hallaba tapado por una losa pétrea que cubría parte de la boca del hoyo. Encima de éste había tierra oscura y fragmentos de hueso. En sus proximidades se localizaron fragmentos de cerámica, procedente de arrastre de otros puntos de la necrópolis. El ajuar lo componen:

- Punta de lanza larga con nervio de sección circular.

- Regatón troncocónico.

- Broche de cinturón de tres garfios, escotaduras cerradas y decoración incisa.

- Hembra serpentiforme.

- Fíbula de tipo 7.A de Argente.

Tumba 327 (Fig. 12 y 13). Es tal vez uno de los conjuntos más expresivos y completos de la necrópolis de Carratiermes, tanto en lo que se refiere a estructura como a elementos del ajuar. El tipo de enterramiento corresponde al de rebaje poco profundo en el conglomerado natural, con cobertera pétrea. No obstante, añade un elemento más, el de la estela, que se hallaba colocada in situ, directamente sobre las piezas del ajuar; alrededor de aquélla, se disponía la cobertera pétrea. A la estela, aunque se encontraba en el lugar original, le faltaba parte de su altura total, cercenada por los arados al realizar sus tareas. El ajuar se disponía en línea, con orientación norte-sur, como es frecuente observar en muchos de los enterramientos excavados. El inventario de piezas es el siguiente:

- Fíbula anular hispánica, tipo 6B de Argente.

- Broche de cinturón, posiblemente de tres garfios y escotaduras cerradas; no se puede afirmar con claridad, ya que está muy estropeado por la acción del fuego.

- Fragmento de hembra de broche de cinturón, tipo serpentiforme. 


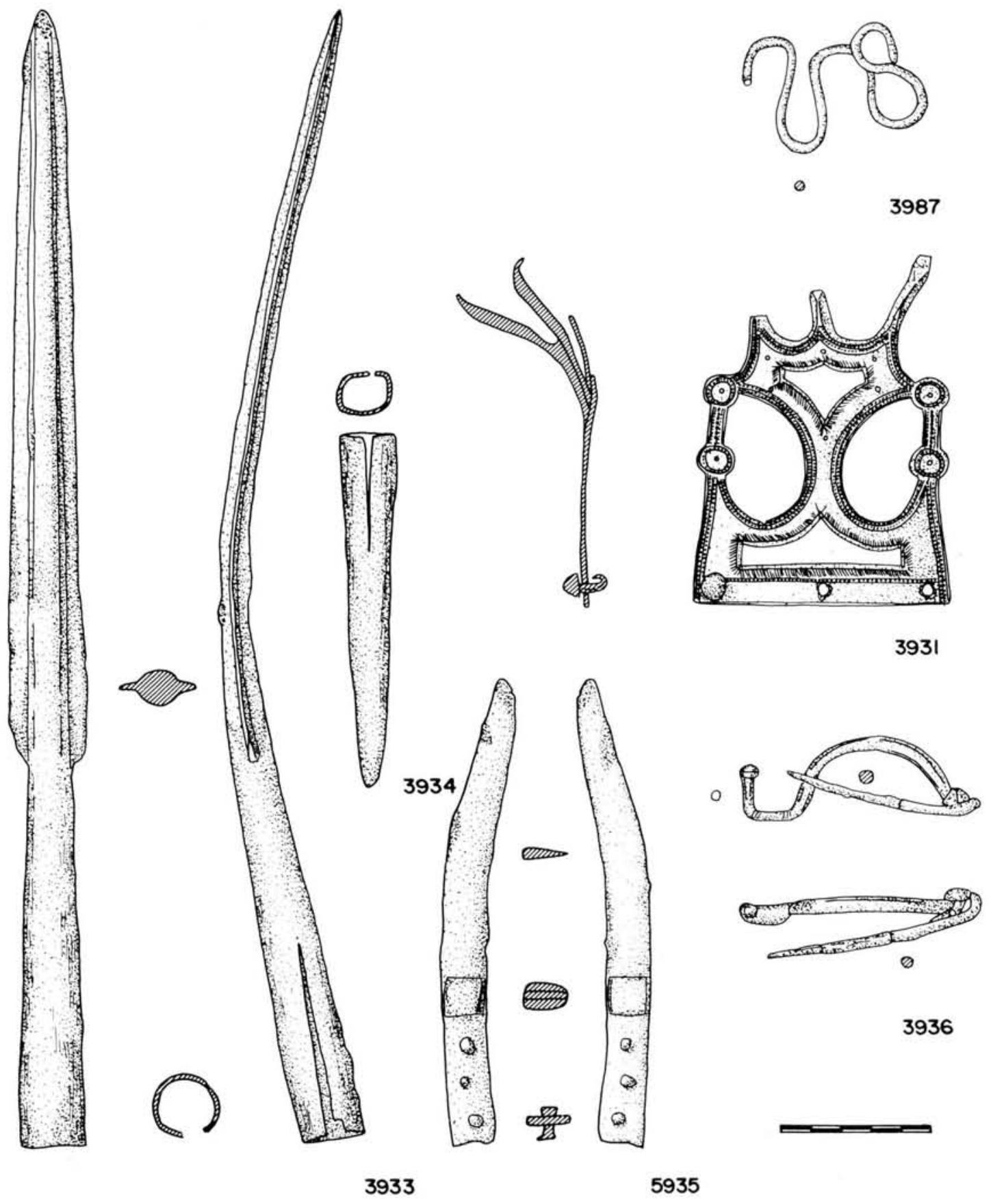

FIG. 11.-Ajuar de armas de la tumba 319.

T. P., $1992, \mathrm{n}^{\circ} 49$ 

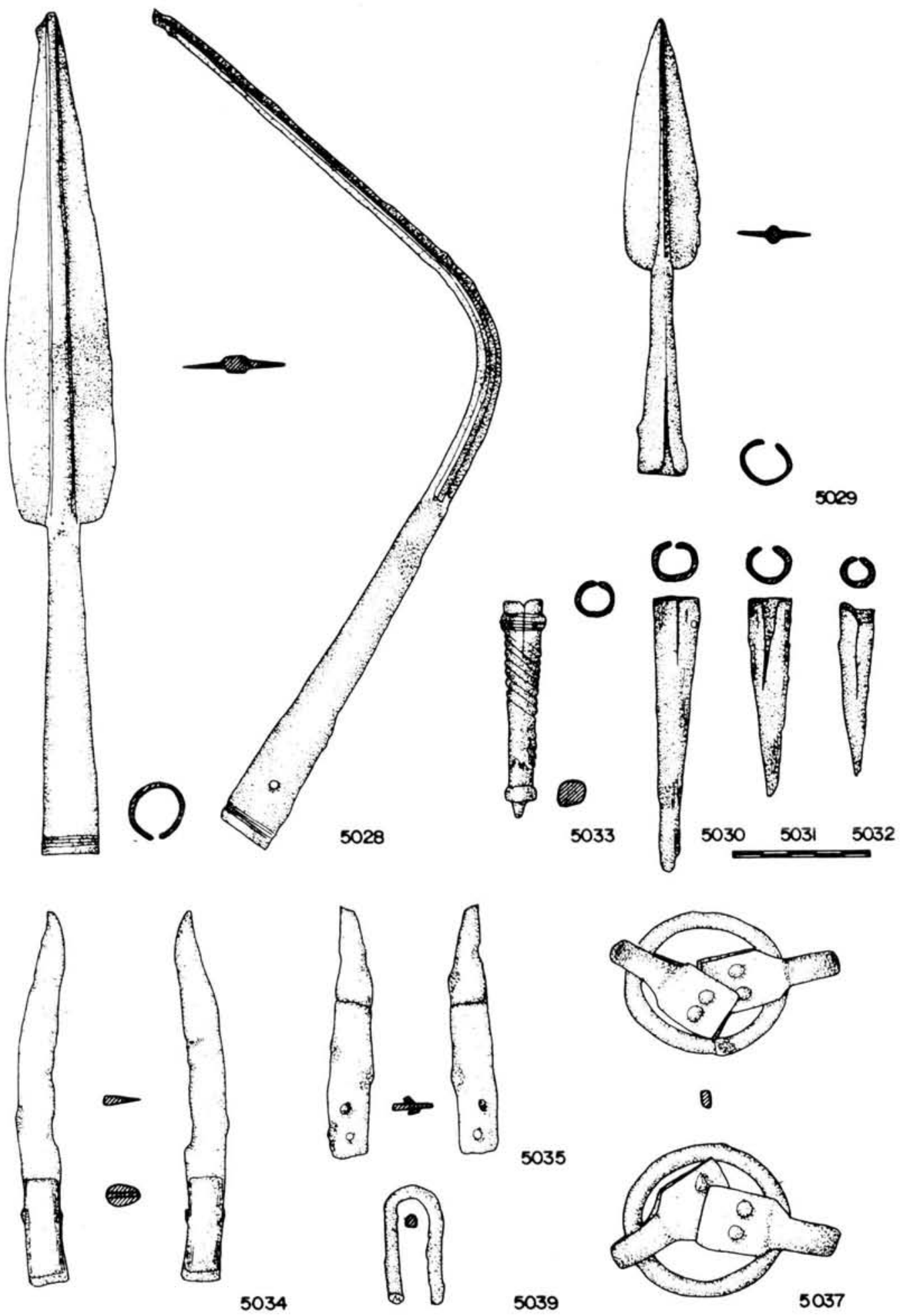

FIG. 12.-Ajuar de armas de la tumba 327.

T. P., 1992, $\mathrm{n}^{\circ} 49$ 

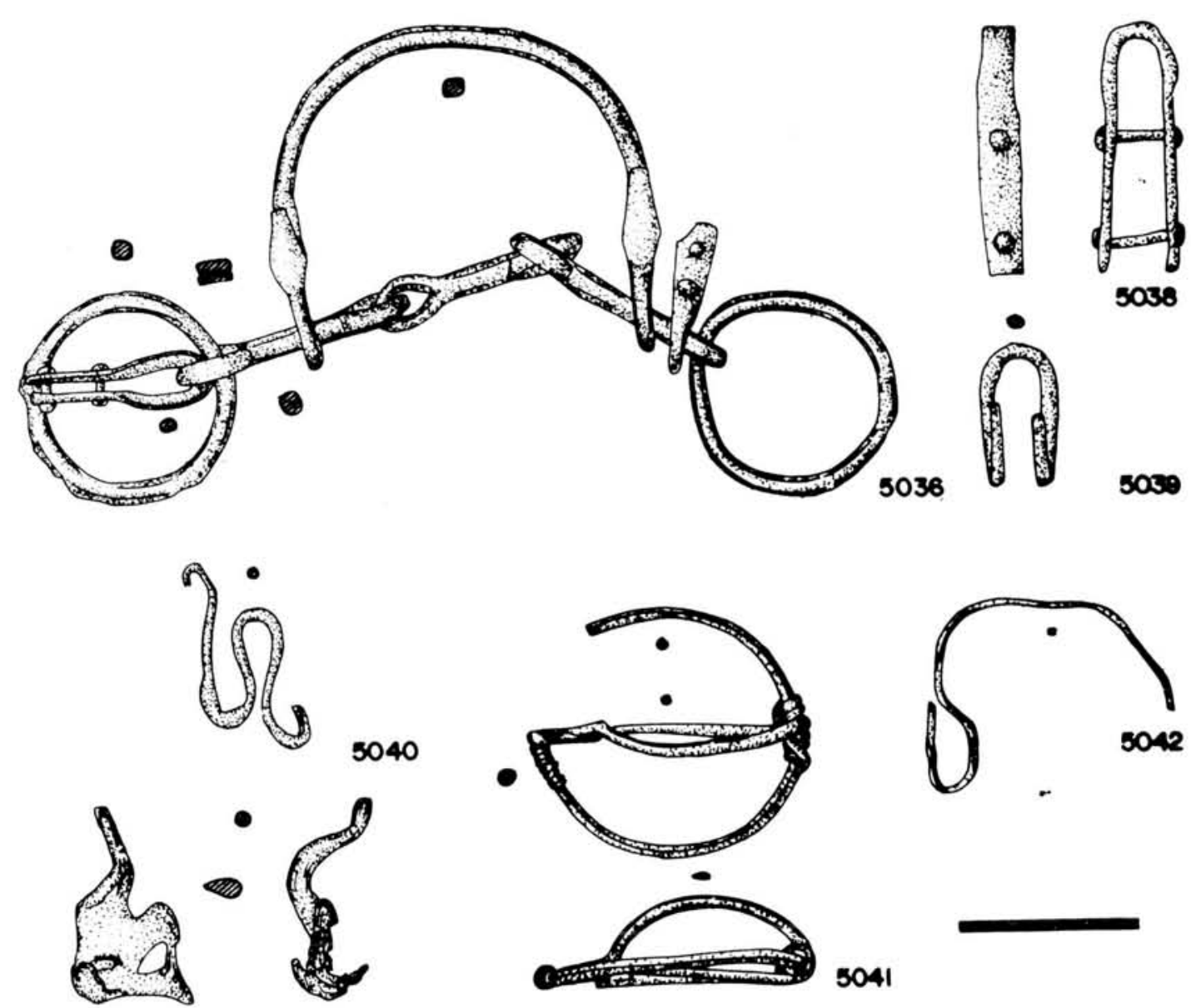

FIG. 13.-Ajuar de armas de la tumba 327.

T. P., 1992, nำ 49 
- Restos de una pieza de bronce, posiblemente de un caldero, que se halló plegado y estaba muy afectado por la acción del fuego, impidiendo un correcto tratamiento de restauración.

- Asa de bronce, pudiera corresponder a la pieza anterior.

- Punta de lanza de hierro, de proporciones amplias.

- Punta de lanza de menor tamaño.

- Cuatro regatones de hierro; uno de ellos decorado a base de un sogueado que recorre su longitud.

- Dos cuchillos de hierro de hoja curva.

- Bocado de caballo de hierro.

- Diversas piezas de hierro de uso indeterminado.

\section{TIPOLOGIA DE LOS ENTERRAMIENTOS}

La organización funeraria registrada en Carratiermes se caracteriza por el uso de diferentes sistemas y formas físicas de enterramiento, que expresamos a continuación. Predomina el uso de la piedra arenisca gruesa frente al uso de la caliza que se va imponiendo en las fases sucesivas:

Hoyo realizado en la matriz arenosa existente en el área que ocupa la necrópolis; está parcial o totalmente relleno de tierra negra, procedente de la incineración. Los huesos de la cremación aparecen ordenados en el hoyo en un lado. Además se presenta el ajuar que, por regla general, consta de piezas fabricadas en bronce, a excepción del cuchillo de hoja curva. Suelen estar cubiertos y rellenos en gran parte por piedras, principalmente areniscas. Aparece claramente descrito por Taracena (Argente Oliver, 1988: t. II: nota 554; transcripción de Taracena Aguirre, inédito) en el diario de la excavación de Almaluez.

Urna con los huesos cremados y el ajuar. Aparecen protegidas con piedras alrededor $\mathrm{y}$, en ocasiones, tapadas por otra piedra. El ajuar puede estar introducido en la urna o en el exterior de ella.

Estela con tumbas asociadas: aunque bien identificado en Carratiermes, no disponemos de muchos ejemplos, ya que, con el transcurso del tiempo y la acción de las tareas agrícolas, se han

\begin{tabular}{|c|c|c|c|c|c|c|c|c|c|c|c|c|c|c|c|c|c|c|c|c|c|c|c|c|c|c|c|c|c|c|c|c|c|c|}
\hline Estructun & - & - & - & $\Delta$ & $\Delta$ & • & - & - & - & • & $\Delta$ & . & - & $\Delta$ & - & - & - & - & - & 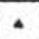 & $\Delta$ & - & - & - & $\bullet$ & • & $\Delta$ & $\Delta$ & - & . & . & $\bullet$ & - & $\Delta$ \\
\hline PECTOAAL & - & - & - & - & घ & - & - & - & - & & - & - & - & - & - & - & v & - & . & - & - & - & - & - & v & - & - & - & - & - & & a & & - \\
\hline Fieula & & & & - & $\bullet$ & & $\bullet$ & - & $\bullet$ & $\bullet$ & $\bullet$ & $\bullet$ & $\bullet$ & $\bullet$ & $\bullet$ & 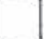 & & & $\bullet$ & - & $\bullet$ & $\bullet$ & $\bullet$ & $\bullet$ & • & $\bullet$ & $\bullet$ & - & $\bullet$ & $\bullet$ & $\bullet$ & $\bullet$ & - & - \\
\hline $\begin{array}{l}\text { BROCHE M } \\
\text { BAOCHE H }\end{array}$ & $\Delta$ & & & $\Delta$ & $\Delta$ & $\Delta$ & & $\Delta$ & & $\Delta$ & $\Delta$ & $\Delta$ & $\Delta$ & $\Delta$ & & $\Delta$ & & & $\Delta$ & & $\Delta$ & $\Delta$ & $\Delta$ & $\Delta$ & $\Delta$ & $\Delta$ & $\Delta$ & $\Delta$ & $\Delta$ & $\Delta$ & $\Delta$ & $\Delta$ & $\Delta$ & $\Delta$ \\
\hline $\begin{array}{l}\text { CUCHILLOO } \\
\text { HOMA CUAVA }\end{array}$ & $\bullet$ & $\bullet$ & & $\bullet$ & $\bullet$ & $\bullet$ & $\bullet$ & & $\bullet$ & & $\bullet$ & $\bullet$ & $\bullet$ & . & $\bullet$ & $\bullet$ & $\bullet$ & & $\bullet$ & $\bullet$ & $\bullet$ & & $\bullet$ & $\bullet$ & $\bullet$ & $\bullet$ & $\bullet$ & & $\bullet$ & & $\bullet$ & $\bullet$ & $\bullet$ & $\bullet$ \\
\hline PulseraA & & $\Delta$ & & & & $\Delta$ & $\Delta$ & & $\Delta$ & & $\Delta$ & $\Delta$ & $\Delta$ & & $\Delta$ & & $\Delta$ & & $\Delta$ & $\Delta$ & & & $\Delta$ & $\Delta$ & & & $\Delta$ & & & & & $\Delta$ & $\Delta$ & \\
\hline $\begin{array}{l}\text { CUEWTAS } \\
\text { COLLAA }\end{array}$ & & & & & & & & & 4 & & 4 & 4 & 4 & & & 4 & & & 4 & $\triangle$ & & $\Delta$ & 4 & & $\Delta$ & 4 & $\Delta$ & & 4 & & & & 4 & 4 \\
\hline $\begin{array}{l}\text { PUNTA OE } \\
\text { LANZA }\end{array}$ & & & & & & & & & & & & & & & & 0 & & & & & 0 & 0 & & & 0 & 0 & 0 & & 0 & & 0 & & 0 & 0 \\
\hline REOATON & & & & & & & & & & 0 & & & & & & a & & & & & D & D & & & 0 & 0 & व & & 0 & & o & & 0 & 0 \\
\hline $\begin{array}{l}\text { BOCADO DE } \\
\text { CABALLOO }\end{array}$ & & & & & & & & & & v & & & & & & & & & & & $\nabla$ & $\nabla$ & & & & $\nabla$ & $\nabla$ & & & & $\nabla$ & & & $\nabla$ \\
\hline URMA & & $\Delta$ & & $\bullet$ & & 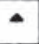 & & $\bullet$ & - & - & 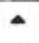 & & - & - & $\bullet$ & 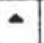 & & - & & & $\Delta$ & & & - & & & & - & & $\Delta$ & & 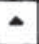 & & $\Delta$ \\
\hline otnos & & & & & & & & & & & & & & & & & & & & & & & & & & & & & & & & & & \\
\hline
\end{tabular}

FIG. 14.-Relación de materiales de las tumbas tomadas como ejemplo para el presente estudio. 
perdido o alterado las estructuras. Se trata de un conjunto de urnas cinerarias cubiertas con piedras de mediano tamaño que se encuentran cobijadas bajo una estela. Siempre se hallan caídas y son de piedra caliza o arenisca, superando en ocasiones el metro y medio. Por debajo del nivel de las urnas, que se apoya en el de grava, se encuentran excavados rebajes con el ajuar metálico, ya sea de armas o de bronces. Hemos de observar que la deposición de las urnas no sería coetánea, conteniendo enterramientos de momentos distintos. En ocasiones se aprecia un ajuar bajo la estela, que debería corresponder al enterramiento principal.

Urna con los huesos solamente y sin ajuar, puede corresponder a tumbas deterioradas por las labores agrícolas o por los enterramientos posteriores.

Hay casos en los que el ajuar metálico del difunto se deposita directamente en el suelo natural del lugar, sin conservar, ni tan siquiera en sus proximidades, estructura funeraria total o parcial; solamente las piezas identifican el enterramiento. Esta información es la que se puede observar en diferentes ejemplos; sin embargo, podemos estimar que lo que nos ha llegado es solamente parte de un todo, faltando no sólo la urna con los restos de la incineración, sino las piedras que conformaban la estructura que protegía el conjunto. Lo que decimos, queda avalado por la excavación de otras tumbas en que se ha conservado integramente la estructura y el ajuar. La pérdida de esta parte se debe a la intervención posterior de los aparatos agrícolas, que han destruído y dispersado una parte del total.

Por otra parte, en esta zona es más frecuente el hoyo, que presenta exclusivamente los huesos, sin ajuar de ningún tipo.

\section{DISTRIBUCION TOPOGRAFICA DE LOS AJUARES PROTOCELTIBERICOS}

La zona excavada en Carratiermes es todavía pequeña en comparación con la superficie total por la que suponemos se extendió la misma; no obstante, se puede indicar algunos datos que creemos pueden ser válidos si, cuando se prosigan los trabajos, continúan en la misma proporción que hasta ahora (Fig. 3).

En la situación actual, se puede señalar que las estructuras protoceltibéricas, tanto las que presentan ajuar de bronce como de guerrero, ocupan unos límites superficiales concretos, en lo que debemos considerar el interior del área a partir de la cual se extiende y dispersa el cementerio, repartiéndose en su entorno los enterramientos de cronología posterior. Aunque todavía no estamos en posición de afirmar si la expansión de la necrópolis se hizo a partir de un punto, sí es cierto que existe una estratigrafía horizontal, no habiendo detectado superposición de estructuras funerarias. Ignoramos también la amplitud del área protoceltibérica en relación a la de etapas posteriores, pero, a partir de los datos confirmados hasta el presente, sí parece diferenciarse una menor ocupación superficial, si para esta consideración nos basamos en el total de las tumbas ya excavadas -superan las 643-, no correspondiendo más de un $25 \%$ a las que pueden situarse en la primera parte de ocupación del cementerio; no obstante, lo único que parece seguro es que alrededor de las estructuras más antiguas se van fijando las que se ubican posteriormente, abriéndose en todas las orientaciones y formando grupos, ya que existen vacíos entre las tumbas excavadas, no pudiendo todavía asegurar si responden a grupos con un lazo de unión determinado - familiar o de otra índole- o simplemente se debe a permitir la existencia de áreas abiertas para poder transitar.

Finalmente, hemos de reseñar que el área ocupada por la zona protoceltibérica es la que mayor densidad de estelas de piedra ha proporcionado, siendo su ausencia casi total entre las estructuras de fechas posteriores. Las estelas suelen hallarse fuera de su primitiva ubicación, caídas sobre las estructuras pétreas o encima de los ajuares; no obstante, algunas de ellas se han localizado in situ, aunque han perdido buena parte de su altura, ya que han sido rotas o seccionadas por acciones posteriores. Las estelas, en los casos que se conservan intactas, se sitúan encima del ajuar metálico o sirven para separar la urna y las piezas que constituyen el mobiliario del difunto. 


\section{CRONOLOGIA DE LOS AJUARES PROTOCELTIBERICOS}

La cronología para las fíbulas de Carratiermes en la etapa protoceltibérica, y dentro de los mobiliarios que relacionamos en el cuadro número 2, se centra en un período general del 575-400 a. C., y en él se incluyen los diferentes tipos correspondientes a la fase protoceltibérica: 3B (550-425 a. C.), 3C (525-400 a. C.), 6B (500 a. C. -50 d. C.) 6C (400-200 a. C.), 7A (550-400 a. C.), 7B (575-400 a. C.) y 9 A1 (525-375 a. C.).

En cuanto a la datación que nos ofrecen los broches, quedan incluidas en un período concreto, que abarca desde el 550 al 400 a. C. Los ejemplares de Carratiermes corresponden a los siguientes tipos, según la clasificación de Cerdeño: C.V.1 ${ }^{\text {a }}$ (550-450 a. C.), D-III. ${ }^{\text {a }}$ (520-400 a. C.), D-III.3 (520-400 a. C.) y D-III.4 (480-450 a. C.) (Cerdeño Serrano, 1978).

La cerámica de Carratiermes nos da un ambiente general de Hierro I, aunque gran parte de ella pueda pervivir en sus formas con la llegada del torno.

\section{CONCLUSIONES}

Todos los elementos de ajuar que hemos venido mencionando entroncan claramente en el periodo entre mediados o fines del s. VI a. C. o inicios del V, hasta la primera mitad del IV a. C., conformando claramente la base del mundo celtibérico.

La pervivencia con los materiales considerados celtibéricos (la cerámica a torno, las espadas de antenas atrofiadas, las fíbulas anulares hispánicas evolucionadas, etc...) demuestra que no hay un momento de ruptura entre lo protoceltibérico y el celtibérico inicial. Sin embargo, ésto no implica que no se produzcan cambios importantes de una fase a otra: la aparición del torno, la generalización de las espadas y las modificaciones formales y tecnológicas en la elaboración de los objetos del ajuar. Estos cambios son atribuidos por la arqueología tradicional a aportaciones de población, sea ibérica (Schulten, Taracena) o céltica (Bosch, Wattemberg). El fenómeno de los movimientos de pueblos es un mecanismo bien establecido para este tipo de sociedades, relacionado con la superpoblación coyuntural y se encuentra documentado en las fuentes y explicado para este tipo de sociedades del Hierro (Champion, 1985).

A pesar de lo anterior, el cambio cultural en la Península no puede ser achacado de un modo generalizado a estas «invasiones" - por otro lado probables-. Junto a una invasión céltica, tanto en la zona Aquitana como en el valle del Ebro (Mohen, 1980; Burillo Mozota, 1987: 85-6), parece desarrollarse también un proceso de progresivo aumento de la influencia ibérica. Taracena - desarrollando la idea de Schulten- propone la llegada de población ibérica (Taracena Aguirre, 1941: 16) que se vería en los cambios de poblamiento, en algunos niveles de destrucción y en el crecimiento de la cultura material de influencia ibérica.

En el estado actual de la cuestión, se tiende a establecer la cronología, los cambios, en relación al poblamiento, las necrópolis y la tipología del material (Romero Carnicero, 1984a; García-Soto Mateos, 1990a), más que a establecer modelos explicativos (un inicio, con un apunte sobre la Meseta Oriental en Burillo Mozota, 1987: 83-85)

Respecto a la diferenciación social existe una evidente gradación entre las tumbas ricas, las cuales poseen incluso enterramientos asociados, y las más pobres, en las que no existe ni urna ni ajuar. Aceptando la hipótesis de que la riqueza del ajuar refleja la posición social del difunto, tenemos en Carratiermes una gradación social clara, más acusada que en la fase celtibérica. Esta diferenciación social no debe exagerarse, toda vez que la información de los poblados no ofrece unas viviendas destacadas de las demás, ni se dan en la zona celtibérica los ricos enterramientos de la cultura ibérica. La riqueza y la entidad de las ciudades del sur permiten el establecimiento de la jerarquía mediante relaciones más directamente económicas que en la Meseta, en la que primarían los lazos sociales como, por ejemplo, el control de la distribución de los bienes de prestigio (Bienes con Valor de Intercambio Social en Frankenstein y Rowlands, 1978). 
Las afirmaciones que aquí hemos efectuado son, si no provisionales, al menos únicamente preliminares y previas al estudio en profundidad de los materiales, su asociación y su distribución en el terreno. Será entonces, sumadas a los resultados de las excavaciones en curso de estudio (Fuensaúco, Zarranzano, la necrópolis de Ucero, las necrópolis y poblados de Guadalajara) cuando se obtenga el cuadro completo de la evolución de la cultura celtibérica desde sus inicios.

Nota P.S.: El presente estudio ha sido elaborado en base a los datos obtenidos tras la campaña de 1989. Actualmente el número de tumbas se ha visto incrementado en casi 200 , por lo que, para una actualización sobre el tema, será necesario acudir a los datos que figurarán en la correspondiente memoria de excavación. Sólo destacar la aparición de una serie de tumbas con pequeñas urnas carenadas y umbito a las que acompañan, como ajuar metálico, fíbulas de doble resorte de puente de cinta; de resorte bilateral sin pie vuelto, del tipo 2.111 de Mohen (1980); del tipo 4 y 5 de Argente (1989). Por último, señalar la presencia de broches de cinturón de un garfio con escotaduras abiertas, aparecidos en tumba, uno de ellos decorados con incisiones gruesas.

\section{BIBLIOGRAFIA}

Aguilera y GamboA, E. DE (Marqués de Cerralbo). (1909): «El Alto Jalón». Madrid.

- (1916): «Las necrópolis ibéricas». Madrid

- (inédita): «Páginas de la Historia Patria, por mis excavaciones arqueológicas».

Almagro Gorbea, M. (1969): «La necrópolis celtibérica de Las Madrigueras, Carrascosa del Campo (Cuenca)». Bibliotheca Praehistorica Hispana.

- (1982): "Los Campos de Urnas en la Meseta». Zephyrus. Actas del Coloquio Internacional sobre la Edad del Hierro en la Meseta Norte, XXXIX-XL: 31-48. Salamanca

Alonso LuBIAS, A. (prensa): «Broches de cinturón de tipo céltico en la necrópolis de Carratiermes». II Symposium de Arqueologia Soriana (Soria, 1989).

ARgenTE Oliver, J. (1974): «Las fíbulas de la necrópolis celtibérica de Aguilar de Anguita». Trabajos de Prehistoria, 31: $145-216$.

- (1986-87): «Hacia una clasificación tipológica y cronológica de las fíbulas de la Edad del Hierro en la Meseta Nortem. Zephyrus. XXXIX-XL: 139-157. Salamanca.

- (1989): «Las fíbulas en la Meseta. Su valoración tipológica, cultural y cronológica». Universidad Complutense, Tesis Doctoral 54/89.

ARgente Oliver, J. L. y Diaz Díaz, A. (1979): «La necrópolis celtibérica de Tiermes (Carratiermes, Soria)». Noticiario Arqueológico Hispánico, 7: 99-151.

- (1990a): «La necrópolis de Carratiermes (Tiermes, Soria)». II Simposio sobre los Celtíberos (Daroca, 1988): 5157. Zaragoza.

- (1990b): «Tiermes, guía del yacimiento arqueológico y Museo». Junta de Castilla y León. Soria.

ARgente Oliver, J. L.; Diaz Diaz, A. y Bescos Corral, A. (1990): «Períodos protoceltibérico y celtibérico en la necrópolis de Carratiermes (Montejo de Tiermes, Soria). Avance de los resultados obtenidos en la campaña de 1989m. Espacio, Tiempo y Forma, S. I Prehistoria y Arqueología, 2: 223-248.

- (1991): "Tiermes. Excavaciones Arqueológicas. Campaña 1991». Junta de Castella y León / Iberdrola I. Soria.

- (prensa): «La necrópolis celtibérica de Carratiermes (Montejo de Tiermes. Soria». II Symposium de Arqueología Soriana (Soria, 1989).

- (prensa): «Placas celtibéricas decoradas en Carratiermes (Montejo de Tiermes. Soria)». II Symposium de Arqueología Soriana (Soria, 1989).

Bosch GIMPERA, P. (1921): «Los celtas y la civilización céltica en la Península Ibérica». Boletín de la Sociedad Española de Excursionistas, XXIX: 248-301.

CABré Aguilo, J. (1917): «Catálogo Monumental de la Provincia de Soria».

- (1930): «Excavaciones en la necrópolis celtibérica del Altillo de Cerropozo, Atienza (Guadalajara)». Memorias de la Junta Superior de Excavaciones y Antigüedades, 105.

- (1932): «Excavaciones en Las Cogotas, Cardeñosa del Campo (Avila) II. La necrópolis». Memorias de la Junta Superior de Excavaciones y Antigüedades, 120

- (1950): «El castro y la necrópolis de Hierro céltico de Chamartín de la Sierra (Avila)». Acta Arqueológica Hispana, V.

CABRE de Morán, E. y Morán CABRÉ, J. A. (1975): «Dos tumbas datables de la necrópolis de Alpanseque (Soria)». Archivo de Prehistoria Levantina, XIV: 123-137.

- (1977): «Fíbulas en las más antiguas necrópolis de la Meseta Oriental Hispánica». Revista de la Universidad Complutense, XXVI, 109: 109-143.

T. P., 1992, $\mathrm{n}^{2} 49$ 
Calvo, I. (1913): "Termes, ciudad celtíbero-arévaca». Revista de Archivos, Bibliotecas y Museos, XXIX: $374-387$.

CAstiella RodrigueZ, A. (1977): "La Edad de Hierro en Navarra y la Rioja». Excavaciones en Navarra, VIII. Pamplona.

Cerdeño Serrano, M. (1978): «Los broches de cinturón peninsulares de tipo céltico». Trabajos de Prehistoria, 35: 279-306.

- (1987): “Materiales cerámicos de una necrópolis celtibérica de Molina de Aragón (Guadalajara)». Wad-alHayara, 14: 269-279.

Díaz Díaz, A. (1976): «La cerámica de la necrópolis celtibérica de Luzaga (Guadalajara), conservada en el Museo Arqueológico Nacional». Revista de Archivos, Bibliotecas y Museos, LXXIX, 2: 397-489.

Fernández Galiano y Valiente Malla, J. (1982): "La necrópolis de la primera edad de Hierro de Prados Redondos (Sigüenza, Guadalajara)". Wad-al-Hayara, 9: 9-48.

Fletcher VALLS, D. (1965): "La necrópolis celtibérica de La Solivella (Alcalá de Chivert, Castellón)». Trabajos varios del Servicio de Investigaciones Prehistóricas, 32: 1-59.

Frankstein, S. y RowlandS, F. (1978): "The internal Structure and regional Context of Early Iron Age Society in South-western Germany". Apud Bulletin of the Institute of Archaeology. 73-112.

García-Soto Mateos, E. (1981): "La necrópolis celtibérica de Ucero (Soria)". Arevacon, 1: 4-9.

- (1990a): "Las necrópolis de la Edad de Hierro en el alto valle del Duero». II Symposium sobre los celtíberos. Las necrópolis (Daroca, 1988). Institución Fernando el Católico: 13-38. Zaragoza.

- (1990b): "Una tumba excepcional de la necrópolis celtibérica de Ucero». II Symposium sobre los celtíberos. Las necrópolis (Daroca, 1988). Institución Fernando el Católico: 59-64. Zaragoza.

GeniERE, J. (1968): «Recherches sur L'Age du Fer en Italie Meridionale. Sala Consilia». Institut Française de Naple. 370.

Gimbutas, M. (1965): «Bronze Age in Central and Eastern Europe». Mouton \& Co. La Haya.

MALUQUeR DE MOTES, J. (1957): «La necrópolis de Atalaya de Cortes». Excavaciones Arqueológicas en Navarra, V.

MARTIN VALLS, R. (1986-87): "La segunda edad del hierro: consideraciones sobre su periodización». Zephyrus. Congreso de la Edad de Hierro en la Meseta, XXXVIII-XXXIX: 59-86. Salamanca.

Mohen, J. P. (1980): "L'Age du Fer en Aquitaine du VIII au III siècle avant J.C.". Memoires de la Sociétè de Préhistoire Française, 14.

MULler-KARPE, H. (1959): "Beitrage zur chronologie der Urnenfelderzeit nordlich und sudlich der Alpen». Walter Gruyter. Berlín.

NASH, D. (1985): "Celtic territorial Expansión and the mediterranean World». En T. C. Champion y J. V. S. Megaw (eds.): Settlement and Society: aspects of West European Prehistory in the first Millennium B.C. Leicester University Press: 45-67.

Palol Salellas, P. y Wattenberg, F. (1974): "Carta Arqueológica de España». Instituto Diego Velázquez, CSIC. Valladolid.

PAZ EsCRIBANO, M. (1980): «La necrópolis céltica de El Atance» (Guadalajara). Wad-Al-Hayara, 7: 35-57.

Pellicer Catalán, M. (1959): "Zaforas, nuevo yacimiento con cerámica excisa en Caspe». V Congreso Nacional de Arqueologia (Zaragoza, 1957). Zaragoza: 138-156.

Peroni, R.; Ponzi, L. Rallo, A.; Coretti, P. y Saronio, P. (1975): «Sulla cronologia delle civiltá d'Este e Golasecca». Istituto Italiano di Preistoria e Protoistoria. Firenze.

RANDALL-MC IVER, D. (1927): "The Iron Age in Italy». Clarendon Press, London.

ROMANONES, Conde de (1910): "Las Ruinas de Termes. Apuntes arqueológicos descriptivos». Madrid.

Romero CARnicero, F. (1980): «Notas sobre la cerámica de la primera Edad del Hierro en la Cuenca media del Duerom. Boletín del Seminario de Arte y Arqueología, XLVI: 137-153.

- (1984a): "La Edad del Hierro en la provincia de Soria. Estado de la cuestión». I Symposium de Arqueología Soriana (Soria, 1982): 25-49. Soria.

- (1984b): «La Edad del Hierro en la Serranía Soriana: Los Castros». Studia Archaeologica, 75.

Ruiz Zapatero, G. (1983): "Los Campos de Urnas de la Península Ibérica». Universidad Complutense. Madrid.

Ruiz Zapatero, G. y LoRrio Alvarado, A. (1988): «Elementos e influjos de tradición de 'Campos de Urnas' en la Meseta Sudorientaln. Actas del Congreso de Historia de Castilla-La Mancha, III: 269-276. Toledo.

Ruiz Zapatero, G. y NuNEZ GARCÍ, C. (1981): "Un presunto ajuar celtibérico procedente de Carratiermes (Soria)». Numantia, I: 189-194. Soria.

SACRISTÁN DE LAMA, J. D. (1987): "La Edad de Hierro en el valle medio del Duero. Rauda (Roa, Burgos)». Junta Castilla y León y Universidad de Valladolid. Valladolid.

Schole, W. (1969): "Die Meseta Kulturen der Iberischen Halbinsel». Mediterrane und Eurische elemente in früheisen-zeitlichen Kulturen Sudwesteuropas». 2 vol. Walter Gruyter, Berlin.

Sanz Minguez, C. (1990): "Rituales funerarios en la necrópolis celtibérica de Las Ruedas, Padilla de Duero (Valladolid)". Necrópolis celtibéricas. II Simposio sobre los celtíberos, Institución Fernando el Católico: 159. 181. Zaragoza.

SENTENACH, N. (1911): "Las ruinas de Termes». Revista de Archivos, Bibliotecas y Museos, XXIV: 205-294.

- (1915): «Excursión a Termes». Boletín de la Sociedad Española de Excursiones, XIX: 176-190.

Taracena Aguirre, B. (1932): "Excavaciones en la provincia de Soria". Memorias de la Junta Superior de Excavaciones y Antigüedades, 119. Madrid. 
- (1941): «Carta Arqueológica de España. Soria». CSIC. Instituto Diego Velázquez. Madrid.

- (inédito): Diario. Cuaderno 6 (1934).

TRUMP, D. (1966): Central and Southern Italy before Rome. Thames \& Hudson. Londres.

VilaseCa ANGUeRA, S. (1953): «Coll del Moro. Yacimiento posthallstáttico». Estudios Ibéricos, 1.

Vilaseca Anguera, S. y Mane Goell, R. et alii (1963): "La necrópolis de Can Canyis. Banyeres, provincia de Tarragonam. Trabajos de Prehistoria, VIII: 7-92

WATTENBERG, F. (1959): «La región vaccea. Celtiberismo y romanización en la cuenca media del Duerom. Bibliotheca Praehistorica Hispana, II. Madrid. 